
\title{
25 Research Square \\ Construction and Properties of Ag-I Polymeric Clusters Attach With Nitrogen Heterocyclic Transition Metal Moiety
}

\author{
Min Liu \\ Liaoning Normal University
}

\section{Yu Xin}

Liaoning Normal University

\section{Yong Heng Xing ( $\nabla$ yhxing2000@yahoo.com )}

Liaoning Normal University https://orcid.org/0000-0002-7550-2262

\section{Fengying Bai}

Liaoning Normal University

\section{Zhan Shi}

Jilin University

\section{Research Article}

Keywords: Silver cluster compounds, Electrochemistry, P-nitrophenol, Catalytic

Posted Date: November 9th, 2021

DOI: https://doi.org/10.21203/rs.3.rs-1035422/v1

License: (c) (1) This work is licensed under a Creative Commons Attribution 4.0 International License. Read Full License

Version of Record: A version of this preprint was published at Journal of Inorganic and Organometallic Polymers and Materials on March 14th, 2022. See the published version at https://doi.org/10.1007/s10904-022-02229-9. 


\section{Abstract}

Two silver cluster compounds $\left\{\left[\mathrm{Co}\left(1,10^{\prime}-\text { phen }\right)_{3}\right]_{2} \otimes\left[\mathrm{Ag}_{8} \mathrm{I}_{12}\right]\right\}$ (1) and $\left\{\left[\mathrm{Co}\left(2,2^{\prime}-\mathrm{bipy}\right)_{3}\right] \rrbracket\left[\mathrm{Ag}_{10} \mathrm{I}_{11}\right] \rrbracket(\mathrm{OH}) \otimes 3 \mathrm{DMF} \otimes\right.$ $2 \mathrm{H}_{2} \mathrm{O}$ (2) (1,10'-phen=1,10'-phenanthroline, 2, 2'-bipy=2,2'-bipyridine) were designed and synthesized by solvent evaporation method. The two silver cluster compounds were characterized by elemental analysis, infrared spectroscopy, ultraviolet spectroscopy, thermogravimetric analysis and X-ray powder diffraction. The crystal structures of compounds 1 and $\mathbf{2}$ were determined by X-ray crystallography diffraction. Through the electrostatic interaction between the metallic Ag cluster moiety and the metallic Co cluster moiety, form stable interlaced layered super molecular structures. In order to explore functional properties, the catalytic reduction of p-nitrophenol and electrochemical behavior of compounds $\mathbf{1}$ and $\mathbf{2}$ were explored. The results show that compounds 1 and $\mathbf{2}$ can efficiently catalyze the reduction of pnitrophenol in the aqueous solution, and the reduction and removal rate can reach more than $90 \%$.

\section{Highlights}

-Synthesis of compounds 1 and $\mathbf{2}$ characterized by single crystal X-ray crystallography in detail.

-1 and 2 through the electrostatic interaction between the metallic Ag cluster moiety and the metallic Co cluster moiety, formed stable interlaced layered super molecular structures.

-1 and 2 can efficiently catalyze the reduction of p-nitrophenol.

\section{Introduction}

Nowadays, with the rapid development of industry, agriculture, and handicrafts, a large amount of hazardous organic wastewater is discharged into the water, causing water pollution, destroying the environmental balance, and even threatening human life and health. Therefore, the development of a catalyst that can efficiently remove organic pollutants has become a current research hotspot ${ }^{[1-2]}$. Catalytic technology is the process of degrading all the pollutants in the aqueous solution into non-toxic substances under the action of a catalyst. These compounds are usually toxic. Discharge into the water will cause water pollution and have carcinogenic effects on humans. Among the many pollutants, nitroaromatic compounds, especially nitrophenol compounds, account for a large proportion. Therefore, the removal of nitroaromatic compounds is particularly important ${ }^{[3-5]}$. So, the degradation and catalytic reduction of p-nitrophenol (PNP) and other nitrophenol compounds have attracted great attention ${ }^{[6-8]}$. As we know, p-nitrophenol (PNP) can be effectively reduced to $p$-aminophenol (PAP). PAP is an effective industrial intermediate, which can be used in analgesic and antipyretic drugs, imaging agents, antiseptic lubricants, etc. In 2016, Sá ${ }^{[9]}$ et al. used molecular hydrogen as a reducing agent for the first time to produce $\mathrm{p}$-aminophenol by continuous flow hydrogenation of $\mathrm{p}$-nitrophenol. This method is to convert a toxic substance into another non-toxic product through an oxidation-reduction reaction, and the byproduct is only water, and water is also a solvent, which provides a new idea for removing p-nitrophenol. In 2016, $\mathrm{Zhu}^{[10]}$ et al. used Ni-Ca- $\mathrm{Al}_{2} \mathrm{O}_{3}$ to catalyze the reduction of p-nitrophenol (PNP). The mechanism 
is that $\mathrm{Ni}-\mathrm{Ca}-\mathrm{Al}_{2} \mathrm{O}_{3}$ catalyzes the release of $\mathrm{H}_{2}$ from $\mathrm{NaBH}_{4}$, and then reduces PNP to p-aminophenol. In 2019, Chen ${ }^{[11]}$ et al. synthesized $\mathrm{W}-\mathrm{TiO}_{2} / \mathrm{SiO}_{2}$ catalyst and studied that it can photo catalyze $\mathrm{p}$ nitrophenol with a mineralization rate of about $99 \%$. P-nitrophenol is first degraded into intermediates by light, and these intermediates are further degraded into smaller fragments such as organic carboxylic acids, and finally fully mineralized. It can be seen that catalytic technology is widely used in the treatment of organic pollutants, and its removal effect is also significant. In 2020 , Feng ${ }^{[12]}$ et al. used nano-pyrite to catalytically reduce $\mathrm{p}$-nitrophenol. Nano-pyrite is dissolved to release $\mathrm{Fe}^{2+}$ under acidic conditions, and then $\mathrm{H}_{2} \mathrm{O}_{2}$ is added. $\mathrm{H}_{2} \mathrm{O}_{2}$ produces a large amount of $\cdot \mathrm{OH}$ under the action of $\mathrm{Fe}^{2+}$, and finally $\cdot \mathrm{OH}$ catalyzes reduction of p-nitrophenol to produce $\mathrm{CO}_{2}$ and $\mathrm{H}_{2} \mathrm{O}$. Eshaq ${ }^{[13]}$ et al. prepared a core-shell nanostructure $\mathrm{FeVO}_{4} @ \mathrm{CeO}_{2}$, which was used as a catalyst to achieve the catalytic reduction and degradation of p-nitrophenol. Catalytic hydrogenation is a method in which $\mathrm{NaBH}_{4}, \mathrm{H}_{2} \mathrm{O}$ or $\mathrm{C}_{2} \mathrm{H}_{5} \mathrm{OH}$ is used as a hydrogen donor to provide active hydrogen for the catalytic process, and then the aromatic nitro compound is catalytically reduced to an aromatic amino compound ${ }^{[14-17]}$. In 2020, Shimoga ${ }^{[18]}$ et al. studied the mechanism of silver nanoparticles (SNPs) catalyzing the PNP process: After sodium borohydride aqueous solution interacts with SNPs, hydrogen gas is rapidly generated and adsorbed on the surface of SNPs, thereby reducing p-nitrophenol on the surface of SNPs. Today, materials such as nanomaterials, graphene, metal oxides and metal organic frameworks have been used as catalysts for the catalytic reduction of $p$-nitrophenol ${ }^{[19-21]}$. Among them, the metal-organic framework has the characteristics of high surface area, high porosity, high stability, etc., which has attracted wide attention. Therefore, looking for an efficient metal-organic framework catalyst has become one of the future research directions.

Nitrogen heterocyclic complexes are metal organic frameworks with specific structures formed by using nitrogen heterocyclic organic compounds as ligands and connecting with the central metal. A simple nitrogen heterocyclic ring is an organic compound containing a five-membered or six-membered heterocyclic structure in the molecule, which means that there is at least one nitrogen atom in the heterocyclic ring ${ }^{[22]}$. Nitrogen heterocyclic ligands can form $\pi-\pi$ interactions between rings to further stabilize the structure of the complex ${ }^{[23-27]}$. In 2016 , Cheng ${ }^{[28]}$ et al. synthesized [ $\left.\left\{R u(b p y)_{2}\right\}_{3}\left(\mu_{3}-L^{2}\right)\right]$ $\left(\mathrm{PF}_{6}\right)_{6}\left(\mathrm{bpy}=2,2^{\prime}\right.$-bipyridine), and studied its photophysical and electrochemical properties. In 2017, Bedowr ${ }^{[29]}$ et al. synthesized [Cu( $\eta^{1}-(\mathrm{OOCR})_{2}\left(2,2^{\prime}\right.$-bpy) $\left(4,4^{\prime}\right.$-bpy $\left.)\right]\left(2,2^{\prime}\right.$-bpy=2,2'-bipyridine, 4, 4'-bpy=4,4'bipyridine), and its magnetic properties were studied. In $2018, \mathrm{Gaml}^{[30]}$ et al. synthesized the complex $\left[\mathrm{Ru}(\mathrm{bpy})_{2}(\mathrm{Hapbim})\right]^{2+}$ (bpy=2,2'-bipyridine, Hapbim is 2-aminophenylbenzimidazole), and measured it by spectrophotometry Optical properties. In 2019, Doyle ${ }^{[31]}$ et al. synthesized $\{[\mathrm{Hphen}][\mathrm{Fe}(\mathrm{phen})$ $\left.\left(\mathrm{H}_{2} \mathrm{P}_{2} \mathrm{O}_{7}\right)_{2}\right] \cdot 2 \mathrm{H}_{2} \mathrm{O}$ ( (phen=1,10'-phenanthroline) and studied its magnetic properties. Yakhvarov ${ }^{[32]}$ et al. synthesized new nickel phosphate complexes $\left[\mathrm{Ni}\left(\mathrm{HPO}_{4}\right)(\mathrm{bpy})_{2}\right]$ and $\left[\mathrm{Ni}\left(\mathrm{HPO}_{4}\right)(\mathrm{phen})_{2}\right]$. The X-ray crystal structure analysis of the complexes showed that the nickel ions have a twisted octahedral complex. The complex structure and diverse functions of silver clusters have attracted wide attention. In 2016, $\mathrm{An}^{[33]}$ et al. used the fluorescence enhancement of the silver nanocluster complex to efficiently detect $\mathrm{Ca}^{2+}$. In 
2017, Zang ${ }^{[34]}$ et al. connected the silver cluster complexes to adaptable ligands to connect them to each other and form a rigid metal-organic framework. Multi-color lights made of volatile organic compounds that are triggered off by oxygen. In 2018, Liang $^{[35]}$ et al. stated in a review that several silver complexes have antibacterial, antifungal, anticancer and other biological activities. In 2020, Weng ${ }^{[36]}$ et al. designed a thermally fluorescent color-changing elastic polymer film by incorporating silver nanoclusters. The color of the polymer film changes when the temperature is higher than $120^{\circ} \mathrm{C}$, and the fluorescence was enhanced. At present, the silver cluster compounds are still under continuous research.

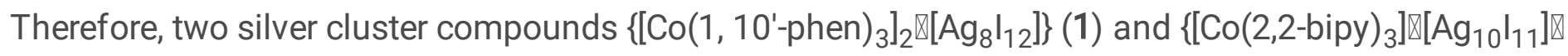
$\left.(\mathrm{OH}) \llbracket 3 \mathrm{DMF} \otimes 2 \mathrm{H}_{2} \mathrm{O}\right\}(2)$ were designed and synthesized based on 1, 10'-phenanthroline and 2, 2区-bipyridine ligands by solvent evaporation method, the electrochemical behavior of 1 and $\mathbf{2}$ and the optimal resting time, $\mathrm{pH}$ and sweep rate of the cyclic voltammetry curve were studied. The catalytic reduction of PNP was also explored, and the catalytic reduction of PNP was also investigated. The mechanism of the process was speculated, the reduction and removal rate can reach more than $90 \%$.

\section{Experimental}

2.1 Materials and method: All chemicals purchased were of reagent grade or better and were used without further purification. Solvents were purified according to the standard methods. The instrument used in this work is in the supporting information.

\subsection{Preparation of 1 and 2}

In this work, 1,10'-phenanthroline and 2,2'-bipyridine were used as ligands, $\mathrm{Agl}_{2}{ }^{-}$was used as the metal source, and the silver cluster compounds 1 and 2 was synthesized by solvent volatilization under the conditions of DMF solvent. The detailed preparation methods of 1 and $\mathbf{2}$ were described in the supporting information. The synthetic route for the compounds 1 and $\mathbf{2}$ were summarized in Scheme 1.

\subsection{Fabrication of electrodes}

The BCPE was made by $0.75 \mathrm{~g}$ of graphite powder and $0.25 \mathrm{~g}$ of paraffin wax. Mixed the two evenly, after 3 times of heating and grinding, put them into a self-made glass tube with a diameter of $3 \mathrm{~mm}$, and finally insert a copper wire ${ }^{[37-38]}$. The same process to prepare the working electrode. During the grinding, add $10 \mathrm{mg}$ of the compound was added to the carbon paste.

Cyclic voltammetry uses a three-electrode system: the reference electrode is a saturated calomel electrode, the counter electrode is a platinum electrode, the working electrode is a carbon paste electrode, and the electrolyte solution is a $1 \mathrm{M} \mathrm{KCl}$ solution. Measure cyclic voltammetry curves at different scanning speeds, different static times and different $\mathrm{pH}$ value ${ }^{[39]}$.

\subsection{Catalytic experiment of compounds}


Add $20 \mathrm{~mL}$ PNP solution and $2 \mathrm{~mL} \mathrm{NaBH}$, solution together, the solution turns bright yellow, and then add a certain amount of compound and ultrasonic for $30 \mathrm{~s}$, and measure the absorbance of the solution at a specific wavelength at different time intervals with an ultraviolet-visible spectrophotometer, calculate the reduction rate of PNP. Figure S1 was standard curve of PNP solution.

\section{Results And Discussion}

\subsection{IR spectra}

The IR spectra of a series of the complexes were shown in Figure S2. In the IR spectrum of 1 , the characteristic peak at $1673 \mathrm{~cm}^{-1}$ is attributed to the $\mathrm{C}=\mathrm{N}$ stretching vibration, while the $\mathrm{C}=\mathrm{N}$ stretching vibration peak of the ligand 1, 10'-phen is at $1654 \mathrm{~cm}^{-1}$. The $\mathrm{C}=\mathrm{N}$ stretching vibration peak of 1 is redshifted compared to the $\mathrm{C}=\mathrm{N}$ stretching vibration peak of ligand 1,10 '-phen, which indicates that the metal $\operatorname{Co}(\mathbb{\nabla})$ is coordinated with the ligand. In the IR spectrum of 2 , the vibration peak at $1663 \mathrm{~cm}^{-1}$ is considered to be the stretching vibration of $\mathrm{C}=\mathrm{N}$, while the $\mathrm{C}=\mathrm{N}$ stretching vibration of ligand 2, 2ख-bipy appears at $1665 \mathrm{~cm}^{-1}$. The $\mathrm{C}=\mathrm{N}$ stretching vibration of 2 is blue-shifted compared to the $\mathrm{C}=\mathrm{N}$ stretching

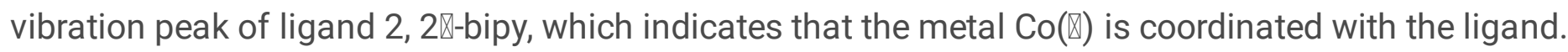
The main infrared data were listed in Table S3.

\subsection{UV-vis spectra}

The UV-Vis spectra of a series of the compounds were shown in Figure S3. The $\pi-\pi^{*}$ transition and $n-\pi^{*}$ transition of the ligand 1, 10'-phen appear at $256 \mathrm{~nm}$ and $325 \mathrm{~nm}$. For 1, the two strong absorption bands at $220 \mathrm{~nm}$ and $261 \mathrm{~nm}$ were attributed to the ligand-to-ligand charge transition (LLCT). The strong absorption band at $376 \mathrm{~nm}$ can be attributed to the ligand-to-metal charge transition (LMCT). It further shows that the metal $\mathrm{Co}(\mathbb{\nabla})$ is coordinated with the ligand 1, 10'-phen. The two strong absorption bands at $218 \mathrm{~nm}$ and $321 \mathrm{~nm}$ are the $\pi-\pi^{*}$ and $n-\pi^{*}$ transitions of 2 , which can be attributed to the ligand-to-ligand charge transition (LLCT). The $\pi-\pi^{*}$ transition and $n-\pi^{\star}$ transition of the ligand 2, 2Х-bipy appear at $264 \mathrm{~nm}$ and $316 \mathrm{~nm}$. The strong absorption band at $411 \mathrm{~nm}$ can be attributed to the ligand-to-metal charge

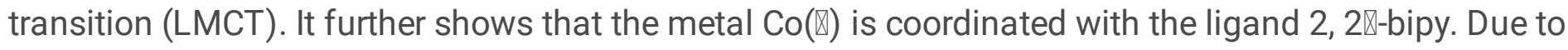
the wavelength limitation of the instrument, the characteristic absorption peak of Co is not shown. The main UV-vis spectra data were listed in Table S4.

\subsection{Powder X-ray diffraction (PXRD)}

The experimental and simulated PXRD patterns of $\mathbf{1}$ and $\mathbf{2}$ are shown in Figure S4. As shown in the Figure S4a and Figure S4b, although the peak intensity of the experimental PXRD pattern and the simulated PXRD pattern are slightly different, the positions of the respective peaks are almost the same. This indicates that $\mathbf{1}$ and $\mathbf{2}$ are pure phase without impurities. At the same time, as shown in Figure S5a and Figure S5b, the crystallinity of 1 and $\mathbf{2}$ was calculated according to the jade 5 software, which were $54.62 \%$ and $74.65 \%$, respectively.

\subsection{Thermogravimetric analyses (TG)}


To verify the thermal stability of the compound, thermogravimetric analysis was performed at a heating rate of $10^{\circ} \mathrm{C} / \mathrm{min}$ under a $\mathrm{N}_{2}$ atmosphere with the temperature range from 30 to $800^{\circ} \mathrm{C}$. The TG curve of 1 was shown in Figure S6a, the first stage of weight loss occurs at $30-560{ }^{\circ} \mathrm{C}$, and the actual weight loss rate is $29.6 \%$ (theoretical weight loss rate: $30.1 \%$ ), which corresponds to the loss of six $1,10^{\prime}$-phen ligands. The second weight loss stage occurs at $560-800{ }^{\circ} \mathrm{C}$, the actual weight loss rate is $8.6 \%$, which corresponds to the collapse of the framework, and the final residue was metal oxide. The TG curve of 2 was shown in Figure S6b, the first stage of weightlessness occurs at $30-150{ }^{\circ} \mathrm{C}$, and the actual weight loss rate is $1.7 \%$ (theoretical weight loss rate: $1.6 \%$ ), which corresponds to the loss of two water and a hydroxide ion. The second stage of weight loss occurs at $150-530{ }^{\circ} \mathrm{C}$, and the actual weight loss rate is $16.9 \%$ (theoretical weight loss rate: $16.0 \%$ ), which corresponds to the loss of three DMF and three 2, 2\bipy. The third weight loss stage occurs at $530-800{ }^{\circ} \mathrm{C}$, the actual weight loss rate is $6.0 \%$, which corresponds to the part collapse of the framework, and the final residue was metal oxide. Comparing the weight loss of $\mathbf{1}$ and $\mathbf{2}$, the thermal stability of $\mathbf{2}$ is relatively better. The main thermogravimetric analyses data were listed in Table S5.

\subsection{Crystal structures of the compounds 1 and 2}

Compound 1 belongs to the monoclinic system with $P 2_{1} / c$ space group. The molecular structure includes a metallic Ag cluster anda Co cluster dimer with six 1,10'-phen. The metal Co atom chelates with six nitrogen atoms (N1-N6) from three 1,10'-phen to form a six-coordinate octahedral configuration, as shown in Fig.1a. The coordination mode of ligand 1, 10'-phen is $\mu_{2}-\eta_{N}{ }^{1} \eta_{N}{ }^{1}$, as shown in Fig.1c. The Ag clusters consist of eight silver ions and twelve iodide ions, as shown in Fig.1b.

In the Ag cluster, both $\mathrm{Ag} 1$ and $\mathrm{Ag} 2$ form a deformed triangular pyramid structure, $\mathrm{Ag} 1$ is coordinated by two $\mu_{2}-1(12,18)$ and one $\mu_{3^{-1}}(13), \mathrm{Ag} 2$ is coordinated by two $\mu_{2}-1(11,12)$ and one $\mu_{3^{-1}}(14)$. Among them, Ag3, Ag4, Ag5, Ag6, Ag7 and Ag8 all form a twisted tetrahedral configuration, Ag3 is coordinated by two $\mu_{2}-1$ $(I 1, I 12)$ and two $\mu_{3}-1(I 3, I 5), A g 4$ is coordinated by three $\mu_{3}-1(I 3-15)$ and one $\mu_{4}-\mathrm{I}(16)$, and Ag5 is coordinated by two $\mu_{2}-1(17,18)$, one $\mu_{3}-1$ (14) and one $\mu_{4}-1$ (16), Ag6 is coordinated to one $\mu_{2}^{-1}(110)$, two $\mu_{3}-1$ $(15,111)$ and one $\mu_{4}-\mathrm{I}(16), \mathrm{Ag} 7$ is coordinated to two $\mu_{2}-\mathrm{I}(17,19)$, one $\mu_{3}-\mathrm{I}(111)$ and one $\mu_{4} \mathrm{I}(16), \mathrm{Ag} 8$ is coordinated to three $\mu_{2}-1(19,110,112)$ and one $\mu_{3}-1$ (I11). The coordination environment of metallic Ag ions is shown in Table S6. The bond length range of Ag-l bond in compound 1 is about 2.709-3.252 $\AA$, which is similar to the bond length range of $\mathrm{Ag}-\mathrm{l}$ bond 2.737-3.181 $\AA$ reported in the literatures ${ }^{[40-42]}$. Six tetrahedral $\mathrm{Agl}_{4}$ and two triangular pyramid $\mathrm{Agl}_{3}$ are connected by sharing edges to form $\mathrm{Ag}_{8} \mathrm{I}_{12}$ building block of Ag cluster. As shown in Fig. $1 \mathrm{~d}$, the $\mathrm{Ag}_{8} \mathrm{I}_{12}$ building blocks are connected by $\mathrm{I}_{12}$ to form a onedimensional chain structure. As shown in Fig. 1e and 1f, a more stable interlaced layered structure is formed between the metal Ag cluster part and the metal Co cluster part through the electrostatic interaction between the anion and the cation.

Compound 2 belongs to the monoclinic system with $C 2 / c$ space group. The molecular structure includes a metal Ag cluster, a metal Co cluster, a hydroxide ion, three free DMF and two lattice water. In the structure, the Co cluster is a cationic cluster with +2 valence. As shown in Fig. $2 \mathrm{a}$, the metal Co atom and 
six nitrogen atoms from three 2, 2Х-bipyridine (N1-N3, N1 ${ }^{\# 1}-\mathrm{N} 3^{\# 1} ; \# 1$ : 1-X, y, 0.5-z) form a six-coordinate octahedral configuration. As shown in Fig. 2c, the coordination mode of ligand 2, 2Х-bipyridine is $\mu_{2}{ }^{-}$ $\eta_{N}{ }^{1} \eta_{N}{ }^{1}$. Ag clusters are anionic clusters with -1 valence and consist of ten silver ions and eleven iodide ions as shown Fig. 2b. In which, Ag1 is coordinated by four $\mu_{4} I\left(11,11^{\# 1}, 12,12^{\# 1}\right)$ to form a tetrahedral configuration. Ag2 is coordinated by a $\mu 2-$ I (I4), a $\mu 3-I$ (I3) and a $\mu 4-I$ (I4) to form a deformed triangular pyramid configuration. Ag3 is coordinated by one $\mu_{2}-\mathrm{I}(14)$ and two $\mu_{3}-\mathrm{I}\left(15,15^{\# 1}\right)$ to form a triangular pyramid configuration. Ag4 is coordinated by a $\mu_{2}-1$ (I4) and a $\mu_{4}-1$ (I6) to form a V shape. Ag5 is coordinated by one $\mu_{3}-\mathrm{I}(13)$ and $\operatorname{six} \mu_{4}-\mathrm{I}\left(11,11^{\# 1}, 12,15,16,16^{\# 1}\right)$ to form a deformed pentagonal biconical configuration. Ag6 is coordinated by one $\mu_{3}-1(13)$ and four $\mu_{4} I(11,12,15,16)$ to form a triangular double cone configuration. The coordination environment of metallic Ag ions is shown in Table S6. The bond length range of $\mathrm{Ag}-\mathrm{l}$ bond in compound $\mathbf{2}$ is 2.736-3.212 $\AA$, which is similar to the bond length range of Ag-l bond (2.737-3.181 $\AA$ ) reported in the literatures ${ }^{[40-42]}$. Two V shaped $\mathrm{Agl}_{2}$, three triangular pyramid configuration $\mathrm{Agl}_{3}$, one tetrahedral configuration $\mathrm{Agl}_{4}$, two triangular biconical configuration $\mathrm{Agl}_{5}$ and two deformed pentagonal biconical configuration $\mathrm{Agl}_{7}$ are connected by the sharing edges to form a "kite Shaped" $\mathrm{Ag}_{10} \mathrm{I}_{11}$ building block. As shown in Fig. $2 \mathrm{~d}$, the building blocks are connected by shared edges Ag3-14 to form a one-dimensional chain structure. Similarly, like the structure of 1, as shown in Fig. 2e and $2 \mathrm{f}$, a more stable interlaced layered super molecular structure is formed between the metal Ag cluster part and the metal Co cluster part through the electrostatic interaction between the anion and the cation.

\subsection{Electrochemical properties of 1 and 2}

Figure 3 is the $\mathrm{CV}$ curve of carbon paste electrode and compounds 1 and 2 electrode in $\mathrm{NaOH}$ electrolyte solution. Compared with the carbon paste electrode, the redox peak of $\mathbf{1}$ and $\mathbf{2}$ appeared. Fig. 3a is the CV curve of 1 , The oxidation peak is at $0.276 \mathrm{~V}$ and its current value is $2.696 \times 10^{-7} \mathrm{~A}$; the reduction peak is at $-0.015 \mathrm{~V}$ and its current value is $-2.407 \times 10^{-7} \mathrm{~A}$. Fig. $3 \mathrm{~b}$ is the $\mathrm{CV}$ curve of 2 . The oxidation potential is at $0.261 \mathrm{~V}$ and the current value is $8.018 \times 10^{-6} \mathrm{~A}$; the reduction potential is at $0.039 \mathrm{~V}$ and the current value is $-1.347 \times 10^{-5} \mathrm{~A}$. According to equation 1 , it can be detected whether the electrode reaction is Nernst reaction. When $T=298 \mathrm{~K}$, it can be simplified to $\triangle E p=59 / z$. When the value of $\triangle E p$ is close to $59 / z$, the electrode reaction is a reversible reaction. The $\triangle E p$ value of 1 is $251 \mathrm{mV}$, the $\triangle E p$ value of 2 is $222 \mathrm{mV}$, and its $\triangle E p$ value cannot be close to $59 / z$, so the electrode reactions of 1 and 2 are all irreversible reactions. In an irreversible reaction, the number of transferred electrons in the oxidation process can be calculated by equation 2. According to equation 1, the number of transferred electrons of $\mathbf{1}$ and $\mathbf{2}$ is calculated to be 1.5 and 1.5, respectively. Therefore, the compounds 1 and $\mathbf{2}$ transfer 1.5 electrons during the oxidation process.

$\Delta E p=2.3 R T / z F(1)$

$|E p-E p / 2|=47.7 /(1-a) n(2)$ 
Where $\triangle E p$ is the difference between oxidation potential and reduction potential $(\mathrm{mV}), R$ is 8.314 $\mathrm{J} /(\mathrm{mol} \cdot \mathrm{K}), T$ is temperature $(\mathrm{K}), z$ is the number of transferred electrons, $F$ is $96500 \mathrm{C} / \mathrm{mol}, E p$ is the oxidation peak Potential $(\mathrm{mV}), E p / 2$ is the half-peak potential $(\mathrm{mV}), \mathrm{a}$ is the electron transfer coefficient, which is approximately 0.5 , and $n$ is the number of transferred electrons.

The Influence of Different Scanning Speed on Cyclic Voltammetry

By studying the CV curves of $\mathbf{1}$ and $\mathbf{2}$ at different scan rates, the CV curve at the best scan rate was determined. It can be seen from Fig. 4 that with the increase of the sweep rate, the peak current of the reduction potential and the oxidation potential of 1 first increase to the maximum and then decrease. At a sweep rate of $0.05 \mathrm{~V} / \mathrm{s}$, the peak current of 1 reaches the maximum and the peak shape is complete. Therefore, the best sweep speed of the CV curve of 1 is $0.05 \mathrm{~V} / \mathrm{s}$. Fig. 5a and Fig. 5b are the CV curves of 2 at different sweep speeds. It can be seen from the figure that the reduction potential and the peak current of the oxidation potential of $\mathbf{2}$ increase with the increase of the sweep rate. When the sweep speed is $0.1 \mathrm{~V} / \mathrm{s}$, the peak current reaches the maximum and the peak shape is complete. Therefore, the best sweep rate for the CV curve of 2 is $0.1 \mathrm{~V} / \mathrm{s}$.

The Influence of Different Resting Time on Cyclic Voltammetry

Through the research on the CV curve of 1 and $\mathbf{2}$ under different resting time, the CV curve under the best resting time is determined. It can be seen from Fig. 6 that the peak currents of the oxidation potential and reduction potential of 1 gradually decrease and then almost remain unchanged when the resting time increases. When the rest time is equal to $5 \mathrm{~s}$, the peak current of the CV curve of 1 reaches the maximum and the peak shape is complete. Therefore, the optimal resting time of the CV curve of 1 is $5 \mathrm{~s}$. It can be seen from Fig. 7 that as the sweep rate increases, the peak current of 2 also decreases, and remains unchanged after decreasing to the minimum. When the sweep speed is $5 \mathrm{~s}$, the peak current reaches the maximum and the peak shape is perfect. Therefore, the optimal resting time of the CV curve of 2 is $5 \mathrm{~s}$.

The influence of different $\mathrm{pH}$ on cyclic voltammetry curve

The CV curves of $\mathbf{1}$ and $\mathbf{2}$ were tested under the condition of phosphate buffer solution of different $\mathrm{pH}$ to study the effect of $\mathrm{pH}$ on the $\mathrm{CV}$ curves of $\mathbf{1}$ and $\mathbf{2}$. It can be seen from Fig. 8 that as the $\mathrm{pH}$ changes from 5 to 6 , the peak current of the reduction potential and oxidation potential of 1 reaches the maximum; as the $\mathrm{pH}$ changes from 6 to 8 , the peak current gradually decreases. Therefore, $\mathrm{pH}=6$ can be used as the optimal $\mathrm{pH}$ for the $\mathrm{CV}$ curve of 1 . It can be seen from Fig. 9 that with the increase of $\mathrm{pH}$, the peak current of 2 also increases, increases to the maximum and then decreases. When the $\mathrm{pH}$ is 8 , the peak current reaches the maximum and the peak shape is good. Therefore, the optimal pH of the CV curve of 2 is 8 .

\subsection{Catalytic reduction of PNP by 1 and 2}

After adding $\mathrm{NaBH}_{4}$ to the PNP solution, the color changed to bright yellow and a characteristic peak appeared at $400 \mathrm{~nm}$. This is because PNP is ionized under alkaline conditions, and a large amount of $\mathrm{H}^{+}$ are released under the condition of the catalyst, and PNP is catalytically reduced to PAP. The 
characteristic absorption peak of PAP is at $298 \mathrm{~nm}$. As shown in Fig. 10, as time increases, the characteristic peak at $400 \mathrm{~nm}$ gradually decreases, while the characteristic peak at $298 \mathrm{~nm}$ gradually increases. This means that the concentration of PNP is gradually decreasing, and the concentration of PAP is increasing. It can be seen that PNP is catalytically reduced to PAP under the combined action of 1 and 2 and $\mathrm{NaBH}_{4}$, and the reduction rates of 1 and $\mathbf{2}$ can reach more than $90 \%$.

The effect of different concentrations of sodium borohydride

Because $\mathrm{NaBH}_{4}$ is a key parameter that controls the entire redox reaction, it is necessary to determine the optimal concentration of $\mathrm{NaBH}_{4}$. A series of catalytic reduction experiments were carried out under the conditions of $\mathrm{NaBH}_{4}$ concentration of 0.1-0.4 M, PNP concentration of $0.1 \mathrm{mM}$ and $5 \mathrm{mg}$ of the compound. As shown in Fig. 11, when the $\mathrm{NaBH}_{4}$ concentrations were $0.1 \mathrm{M}, 0.2 \mathrm{M}$, and $0.4 \mathrm{M}$, the removal rates of PNP by the catalytic reduction of 1 were $95.7 \%, 94.4 \%$ and $97.4 \%$, respectively. As the concentration of $\mathrm{NaBH}_{4}$ increases, the removal rate of catalytic reduction of PNP does not change significantly. Taking into account the length of the reduction time, the optimal concentration of $\mathrm{NaBH}_{4}$ for the catalytic reduction of PNP in 1 was determined to be $0.2 \mathrm{M}$. As shown in Fig. 12, when the $\mathrm{NaBH}_{4}$ concentration is $0.1 \mathrm{M}, 0.2 \mathrm{M}$, and $0.4 \mathrm{M}$, the removal rate of PNP by the catalytic reduction of 2 is $30.1 \%$, $92.9 \%$, and $99.3 \%$, respectively. As the concentration of $\mathrm{NaBH}_{4}$ increases, the removal rate of catalytic reduction PNP also increases, but the removal rate of $0.2 \mathrm{M}$ and $0.4 \mathrm{M} \mathrm{NaBH}_{4}$ does not change much. Taking into account the utilization of the compound, the optimal concentration of $\mathrm{NaBH}_{4}$ for the catalytic reduction of PNP in 2 was determined to be $0.2 \mathrm{M}$.

The effect of different concentrations of PNP

In order to determine the optimal concentration of PNP in the catalytic reduction process, a series of catalytic reduction experiments were carried out under the condition that the $\mathrm{NaBH}_{4}$ concentration was $0.2 \mathrm{M}$ and the $5 \mathrm{mg}$ compound was unchanged. As shown in Fig. 13, when the PNP concentrations were $0.05 \mathrm{mM}, 0.1 \mathrm{mM}$, and $0.15 \mathrm{mM}$, the removal rate of PNP by the catalytic reduction of 1 was $97.0 \%$, $94.4 \%$, and $90.1 \%$, respectively. As the PNP concentration increases, the removal rate of catalytic reduction PNP decreases, but the removal rate does not change much. The time for catalytic reduction of $0.15 \mathrm{mM}$ PNP solution of $\mathbf{1}$ is $70 \mathrm{~min}$, which is relatively long, while the time for catalytic reduction of both $0.05 \mathrm{mM}$ and $0.1 \mathrm{mM}$ PNP solutions is $15 \mathrm{~min}$. Taking into account the length of the reduction time and the utilization of the compound, the optimal PNP concentration for the catalytic reduction of 1 was determined to be $0.1 \mathrm{mM}$. As shown in Fig. 14, when the PNP concentration is $0.05 \mathrm{mM}, 0.1 \mathrm{mM}$, and 0.15 $\mathrm{mM}$, the removal rate of PNP by the catalytic reduction of 2 is $100 \%, 92.9 \%$, and $62.8 \%$, respectively. With the increase of PNP concentration, the removal rate of PNP by the catalytic reduction of 2 decreases. When 2 is used for catalytic reduction of $0.05 \mathrm{mM}$ PNP solution, the reduction time is $2 \mathrm{~min}$, which does not make full use of the compound. When catalytic reduction of $0.15 \mathrm{mM}$ PNP solution, the reduction time is longer and the reduction rate is lower. Taking into account the utilization of the compound and the 
reduction removal rate, the optimal PNP concentration for the catalytic reduction of $\mathbf{2}$ was determined to be $0.1 \mathrm{mM}$.

The influence of the amount of different catalysts

In order to make full use of the reducibility of the compound, the optimal dosage of the compound in the catalytic reduction of PNP was determined. A series of catalytic reduction experiments were carried out under constant conditions of $\mathrm{NaBH}_{4}$ concentration of $0.2 \mathrm{M}$ and PNP concentration of $0.1 \mathrm{mM}$. As shown in Fig. 15, in the case of $3 \mathrm{mg}, 5 \mathrm{mg}$, and $10 \mathrm{mg}$ of 1, the removal rates of catalytic reduction of PNP are $83.4 \%, 94.4 \%$, and $97.7 \%$, respectively. With the increase of the amount of 1 , the removal rate of catalytic reduction PNP increases, but the degree of removal rate changes little. Taking into account the length of the reduction time and the utilization of the compound, the optimal dosage of 1 was determined to be 5 mg. As shown in Fig. 16, in the case of $3 \mathrm{mg}, 5 \mathrm{mg}$, and $10 \mathrm{mg}$ of 2, the removal rate of PNP by the catalytic reduction of $\mathbf{2}$ is $48.6 \%, 92.9 \%$, and $100 \%$, respectively. As the amount of $\mathbf{2}$ increases, the removal rate of catalytic reduction of PNP increases. When $10 \mathrm{mg}$ of 2 is used for catalytic reduction of PNP solution, the reduction time is very short, and it is useless to make full use of the compound. When 3 $\mathrm{mg}$ of $\mathbf{2}$ is used for catalytic reduction of PNP solution, the reduction time is longer and the reduction rate is lower. Therefore, considering the utilization and reduction rate of the compound, the optimal dosage of 2 was determined to be $5 \mathrm{mg}$.

\subsection{Kinetic Study of Catalytic Reduction Process}

In order to analyze the kinetic behavior of the catalytic reduction of PNP solution by $\mathbf{1}$ and $\mathbf{2}$, we used the quasi-first-order kinetic equation 3 and the quasi-second-order kinetic equation 4 to linearly fit the catalytic reduction process of PNP, and we obtained Fig. 17 and other related parameters Table 1.

$\ln \left(C_{t} / C_{0}\right)=-k_{1} t(3)$

$1 / C_{t}-1 / C_{0}=k_{2} t(4)$

Where $C_{e}(\mathrm{~mol} / \mathrm{L})$ represents the equilibrium concentration, $C_{t}(\mathrm{~mol} / \mathrm{L})$ represents the concentration at a certain moment, $k_{1}\left(\mathrm{~min}^{-1}\right)$ and $k_{2}(\mathrm{~L} /(\mathrm{mol} / \mathrm{min}))$ represent the rate constant respectively, $t(\mathrm{~min})$ Is the reaction time.

It can be seen from Fig. 17 that the $R^{2}$ values of the pseudo-first-order kinetic equation fitted by the catalytic reduction of PNP by 1 and 2 are 0.9952 and 0.9901 , respectively, which are closer to 1 than the $R^{2}$ value of the pseudo-second-order kinetic equation. This indicates that the catalytic reduction of PNP solution by 1 and 2 conforms to the quasi-first order kinetic model. 
Table 1

Correlation data of pseudo-first-order and pseudo-second-order kinetics

\begin{tabular}{|lllll|}
\hline Compounds & \multicolumn{2}{l|}{$\begin{array}{l}\text { Pseudo first-order kinetics } \\
\text { model }\end{array}$} & \multicolumn{3}{c|}{ Pseudo secondary-order kinetics model } \\
\cline { 2 - 5 } & $\boldsymbol{k}_{\mathbf{1}}\left(\mathrm{min}^{-1}\right)$ & $\boldsymbol{R}^{2}$ & $\boldsymbol{k}_{\mathbf{2}}(\mathbf{g} /(\mathrm{mg} 囚 \mathrm{~min}))$ & $\boldsymbol{R}^{2}$ \\
\hline $\mathbf{1}$ & 0.1797 & 0.9952 & 10.862 & 0.905 \\
\hline $\mathbf{2}$ & 0.1044 & 0.9901 & 5.5104 & 0.9592 \\
\hline
\end{tabular}

\subsection{Study on the mechanism of catalytic reduction of PNP}

In order to better understand the process of the catalytic reduction of PNP solution by $\mathbf{1}$ and $\mathbf{2}$, we speculated on the mechanism of the catalytic reduction process. It can be seen from the above that the compounds 1 and 2 exhibits good redox properties. Therefore, the mechanism of the catalytic reduction of PNP by 1 and 2 is: $\nabla$ ) The silver cluster in compound 1 and 2 oxidizes $\mathrm{BH}_{4}{ }^{-}$to $\mathrm{BO}_{2}{ }^{-}$and releases $\mathrm{H}^{+}$; ii) $\mathrm{H}^{+}$further de-catalytically reduces the PNP solution ${ }^{[43]}$. It becomes a PAP solution and emits hydrogen gas.

\section{Conclusions}

This work uses solvent evaporation method to design and synthesize two silver cluster compounds $\left\{\left[\mathrm{Co}\left(1,10^{\prime}-\text { phen }\right)_{3}\right]_{2} \otimes\left[\mathrm{Ag}_{8} \mathrm{I}_{12}\right]\right\}$ (1) and $\left\{\left[\mathrm{Co}\left(2,2^{\prime} \text {-bipy }\right)_{3}\right] \otimes\left[\mathrm{Ag}_{10} \mathrm{I}_{11}\right] \otimes(\mathrm{OH}) \otimes 3 \mathrm{DMF} \otimes 2 \mathrm{H}_{2} \mathrm{O}\right\}$ (2). The compounds 1 and 2 form an infinite two-dimensional planar structure through the electrostatic interaction between anion and cation. Compounds 1 and 2 can efficiently catalytically reduce PNP in aqueous solution, and the reduction removal rate can reach more than $90 \%$. At the same time, kinetic analysis showed that the catalytic reduction of PNP by 1 and $\mathbf{2}$ fits well with the quasi-first-order kinetic model. The redox properties of $\mathbf{1}$ and $\mathbf{2}$ were determined by cyclic voltammetry curve. Therefore, the mechanism of the catalytic reduction of PNP by $\mathbf{1}$ and $\mathbf{2}$ is that the silver cluster anion in $\mathbf{1}$ and $\mathbf{2}$ deoxidizes $\mathrm{BH}_{4}{ }^{-}$through its own oxidative property and releases $\mathrm{H}^{+}$, and then $\mathrm{H}^{+}$catalytically reduces PNP to PAP, which releases hydrogen. Therefore, the compounds 1 and 2 can be used as a reducing agent for efficiently removing PNP in aqueous solution, and has good application prospects.

\section{Declarations}

\section{Conflicts of interest}

There are no conflicts to declare.

\section{Acknowledgments}

This work was supported by the grants of the National Natural Science Foundation of China (No.21571091), Liaoning Normal University High-end Scientific Research Achievement Funding Program 
(No. 21GDL003), and Open Project of State Key Laboratory of Inorganic Synthesis and Preparative Chemistry, College of Chemistry, Jilin University in China (No. 2020-10).

\section{Supporting Information}

The following files are available free of charge CCDC 2114111 and 2115232 contains the supplementary crystallographic data for this paper. These data can be obtained free of charge from The Cambridge Crystallographic Data Centre via www.ccdc.cam.ac.uk/data_request/cif. Full experimental details are presented in the Supporting Information.

\section{Declaration of interests}

QThe authors declare that they have no known competing financial interests or personal relationships that could have appeared to influence the work reported in this paper.

QThe authors declare the following financial interests/personal relationships which may be considered as potential competing interests:

The authors declared that they have no conflicts of interest to this work.

\section{Credit author statement:}

Min Liu, experiment, process data, writing; Yu Xin, reviewing; Yong Heng Xing, reviewing and editing, supervision; Feng Ying Bai, reviewing and editing, supervision; Zhan Shi, software.

\section{References}

1. P. Yang, T.T. Nie, J. Hu, H.Q. Ni, J.J. Shi, Funct. Mater. Lett. 13, 1950091.1-1950091.3 (2020)

2. L. Tan, A.D. Tang, Y. Zou, M. Long, Y. Zhang, J.O. yang, J. Chen, Sci. Rep. 7, 3281 (2017)

3. T.H. Zhao, F.H. Zhang, J. Zhou, X.Q. Zhao, Comments Inorg. Chem. 41, 1-33 (2020)

4. P.P. Guo, M. Liu, L.L. Shi, J. Solid State Chem. 286, 121247 (2020)

5. H.A. Alidağı, S.O. Tümay, A. Şenocak, S. Yeşilot, Dyes Pigm. 153, 172-181 (2018)

6. Z.M. Shammi, A.H. Kianfar, M.M. Momeni, J. Mater. Sci. Mater. Electron. 31, 14810-14822 (2020)

7. Y. Gu, Y.Q. Jiao, A.P. Wu, X.G. Zhou, B. Buhe, T.W. Yin, B.J. Jiang, Y. Qu, C.G. Tian, Res. Chem. Intermed. 43, 4759-4779 (2017)

8. S. Alghool, H.F. Abd El-Halim, A.M. Mostafa, J. Inorg. Organomet. Polym Mater. 29, 1324-1330 (2019)

9. C. Paun, G. Słowik, E. Lewin, J. Sá, RSC Adv. 6, 87564-87568 (2016)

10. J. Feng, Q. Wang, D.L. Fan, L.R. Ma, D.L. Jiang, J.M. Xie, J.J. Zhu, Appl. Surf. Sci. 382, 135-143 (2016) 
11. U.A. Sánchez, L.F. Chen, J.A. Wang, L.E. Noreña, M. Asomoza, S. Solis, X.L. Zhou, Y.Q. Song, J. Liu, Int. J. Photoenergy, 2019, 1-13 (2019)

12. T. Liu, N. Chen, Y. Deng, F.X. Chen, C.P. Feng, RSC Adv. 10, 15901-15912 (2020)

13. G. Eshaq, S.B. Wang, H.Q. Sun, M. Sillanpaa, Journal of Hazardous Materials, 382, 121059.1$121059.14(2020)$

14. W.M. Zhang, Z.W. Zhou, X.Y. Shan, R. Xu, Q. Chen, G.Y. He, X.Q. Sun, H.Q. Chen, New J. Chem. 40, 4769-4774 (2016)

15. J.Y. Du, Y. Zhao, J. Chen, P. Zhang, L.L. Gao, M.Q. Wang, C. Cao, W. Wen, C.Q. Zhu, RSC Adv. 7, 33929-33936 (2017)

16. J.W. Sun, J.S. Xu, A. Grafmueller, X. Huang, C. Liedel, G. Algara-Siller, M. Willinger, C. Yang, Y.S. Fu, X. Wang, M. Shalom, Appl. Catal. B Environ. 205, 1-10 (2017)

17. J.S. Wu, J.S. Wang, T.N. Wang, L.M. Sun, Y.C. Du, Y.L. Li, H.Y. Li, Appl. Surf. Sci. 466, 342-351 (2019)

18. G. Shimoga, R.R. Palem, S.H. Lee, S.Y. Kim, Metals 10, 1661 (2020)

19. A.R. Zeng, A.R. Zeng, Water Air Soil Pollut. 8, 278.1-278.17 (2017)

20. M. Lei, W. Wu, S.L. Yang, X.G. Zhang, Z. Xing, F. Ren, X.H. Xiao, C.Z. Jiang, Part. Part. Syst. Charact. 33, 212-220 (2016)

21. T.L. Guo, C. Wang, N.N. Zhang, Y. Zhang, T. Chen, X. Xing, Z.D. Lu, L.L. Wen, Cryst. Growth Des. 9, 6217-6225 (2020)

22. Y. Chen, X.L. Chi, Y.C. Xu, X.C. Wang, D.R. Xiao, Z. anorg. allg. Chem. 642, 128-133 (2016)

23. S.X. Zhao, J.S. Wu, W.Z. Chen, J. Organomet. Chem. 848, 249-280 (2017)

24. K. Laxman, A. Kumar, M. Ravikanth, Asian J. Org. Chem. 9, 162-180 (2020)

25. R. Lopes, Á Raya-Barón, M.P. Robalo, C. Vinagreiro, S. Barroso, M.J. Romão, L. Fernández, M.M. Pereira, B. Royo, Eur. J. Inorg. Chem. 2021, 22-29 (2020)

26. P. Sánchez, Martín Hernández-Juárez, Nuria Rendón, Joaquín López-Serrano, Laura L Santos, Eleuterio Álvarez, Margarita Paneque, Andrés Suárez. Dalton Trans. 49, 9583-9587 (2020)

27. W.S. Ouyang, J.H. Rao, Y.B. Li, X.H. Liu, Y.P. Huo, Q. Chen, X.W. Li, Adv. Synth. Catal. 362, 5576-5600 (2020)

28. F.X. Cheng, S.W. Yu, M.L. Ren, C.X. He, H.J. Yin, Transit. Met. Chem. 41, 305-314 (2016)

29. N.S. Bedowr, R.B. Yahya, N. Farhan, J. Saudi Chem. Soc. 22, 255-260 2018

30. S.A. Elsayed, E.A. Gaml, M.A. Nasher, Opt. Mater. 84, 8-15 (2018)

31. T.J. Greenfield, M.M. Turnbull, J. Zubieta, R.P. Doyle, Inorg. Chim. Acta 498, 119084 (2019)

32. Z.N. Gafurov, A.B. Dobrynin, I.F. Sakhapov, A.A. Kagilev, A.O. Kantyukov, A.A. Balabaev, A.V.

Toropchina, O.G. Sinyashin, D.G. Yakhvarov, Phosphorus Sulfur Silicon Relat. Elem. 194, 517-521 (2019)

33. L. Lu, X.Q. An, W.X. Huang, Anal. Methods 9, 23-27 (2017) 
34. R.W. Huang, Y.S. Wei, X.Y. Dong, X.H. Wu, C.X. Du, S.Q. Zang, T.C.W. Mak, Nat. Chem. 9, 689-697 (2017)

35. X.X. Liang, S.X. Luan, Z.Q. Yin, M. He, C.L. He, L.Z. Yin, Y.F. Zou, Z.X. Yuan, L.X. Li, X. Song, C. Lv, W. Zhang, Eur. J. Med. Chem. 157, 62-80 (2018)

36. L.B. Wang, H. Chen, Q.Y. Yin, J. Kang, B. Liu, G.S. Weng, J. He, Nanotechnology 31, 245703 (2020)

37. T.S. Sunil Kumar Naik, B.E. Kumara Swamy, J. Electroanal. Chem. 826, 23-28 (2018)

38. M. Kumar, M. Wang, B.E. Kumara Swamy, M. Praveen, W. Zhao, Colloids Surf. B Biointerfaces 196,

111299 (2020)

39. K. Chetankumar, B.E. Kumara Swamy, S.C. Sharma, Mater. Chem. Phys. 252, 123231 (2020)

40. D.D. Yang, W.L. Xu, X.W. Cao, S.J. Zheng, J.G. He, Q. Ju, Z.L. Fang, W. Huang, Inorg. Chem. 16, 79547961 (2016)

41. J.J. Shen, C.F. Zhang, T.L. Yu, L. An, Y.L. Fu, Cryst. Growth Des. 12, 6337-6342 (2014)

42. Q. Wei, D. Wang, J. Pan, S.D. Han, G.M. Wang, Chem. Asian. J. 14, 640-646 (2019)

43. C. Kästner, A.F. Thünemann, Langmuir 29, 7383-7391 (2016)

\section{Figures}

(a)
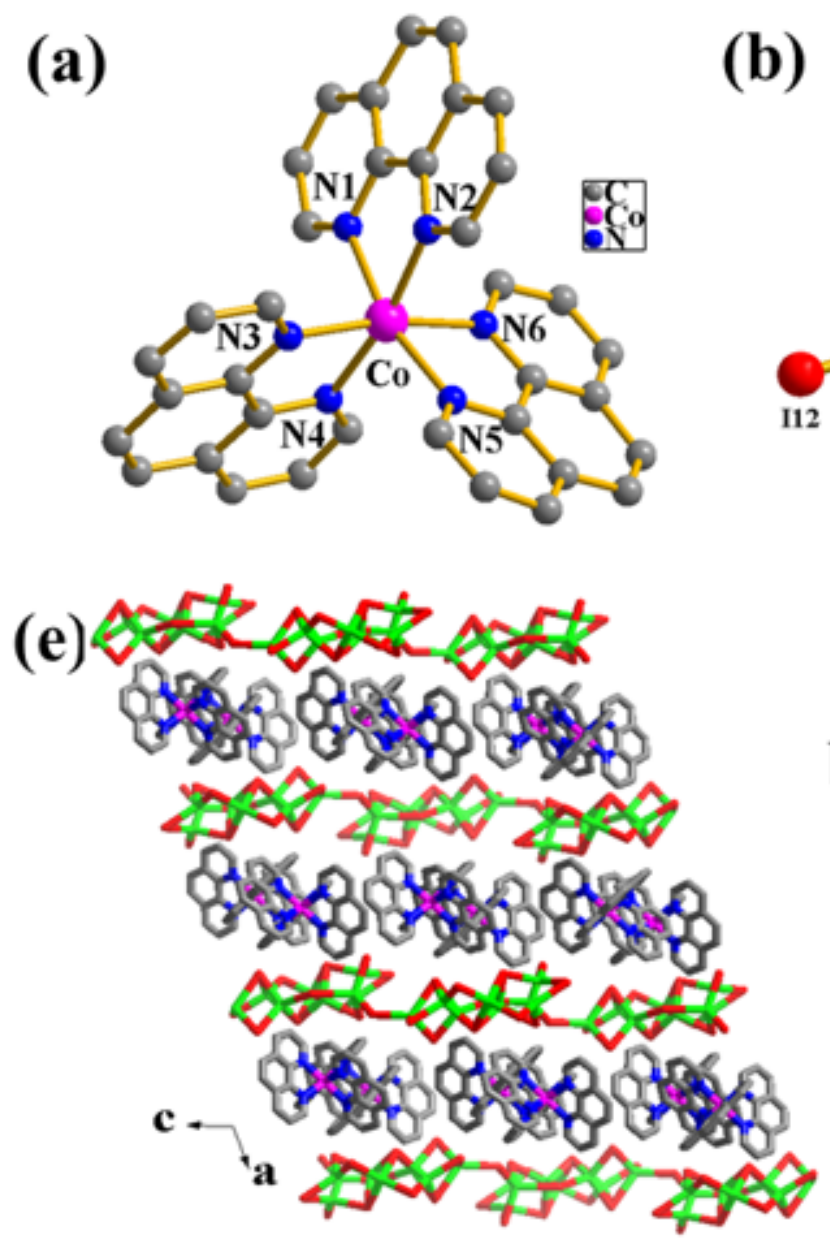

(b)

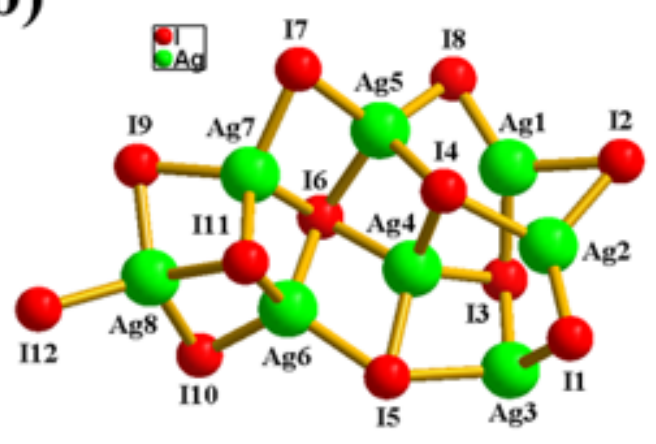

(c)

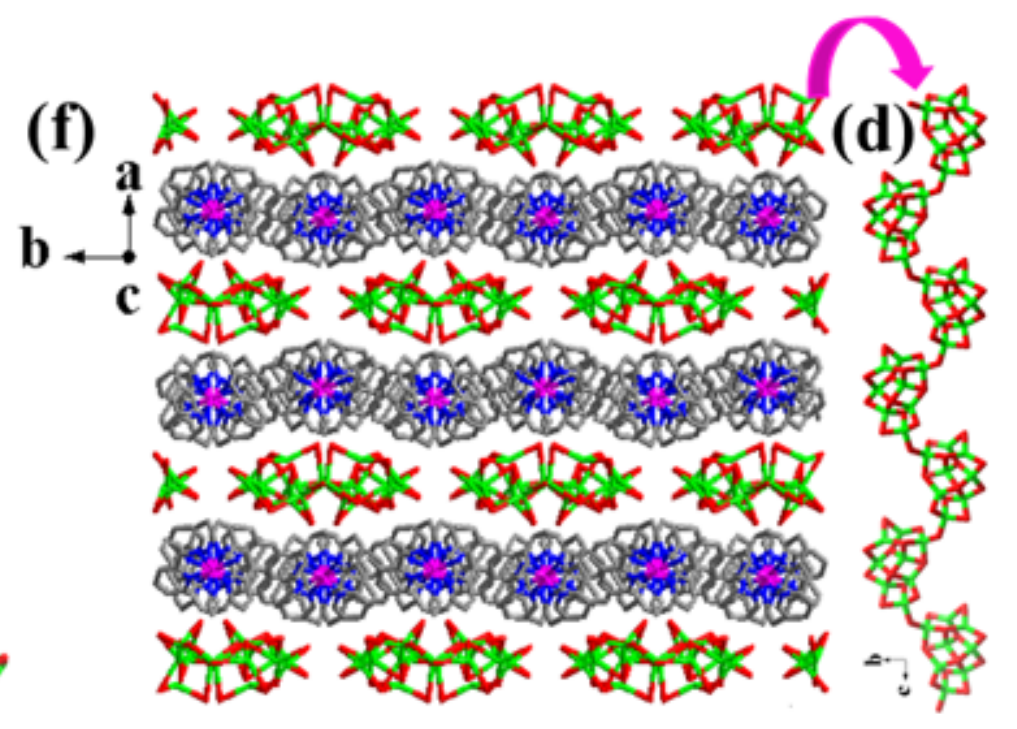


Figure 1

Compound 1: (a) The coordination environment of metal Co; (b) The coordination environment of metal Ag; (c) The connection mode of ligand phen; (d) 1D chain structure;(e) 2D layered structure; (f) 2D layered structure

(a)

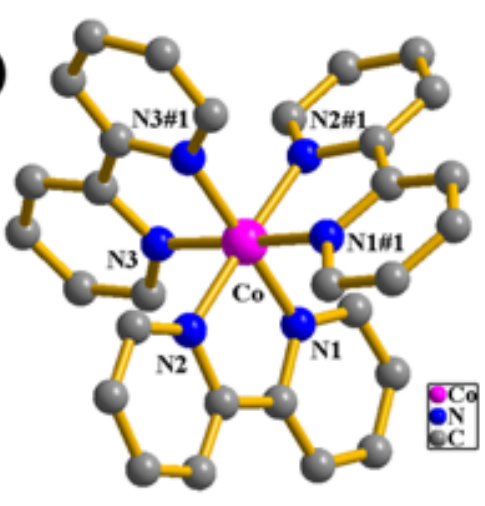

(e)

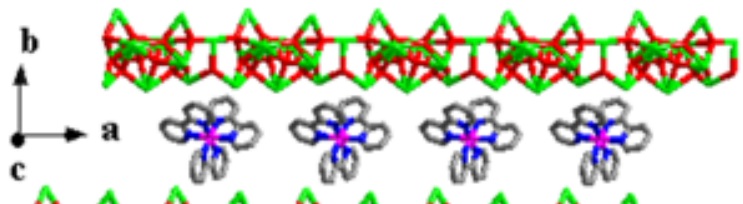

N.

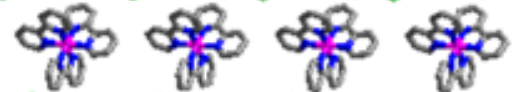

से

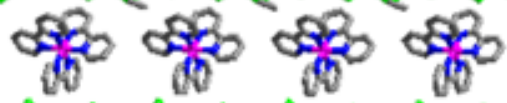

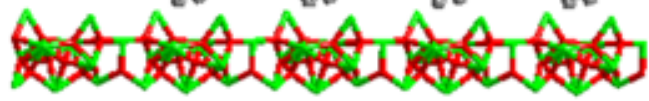

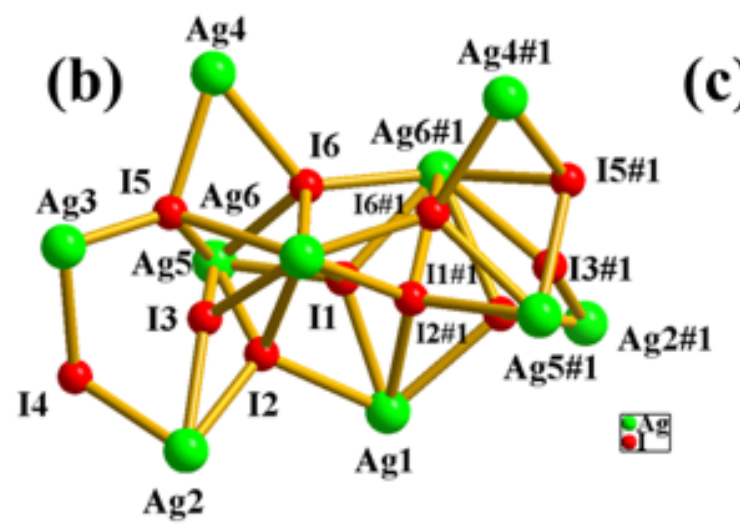

(c)

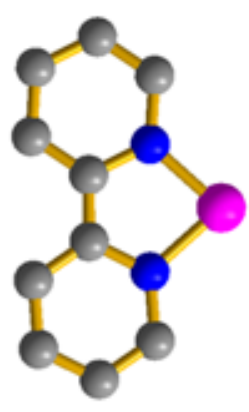

(d)

(f)

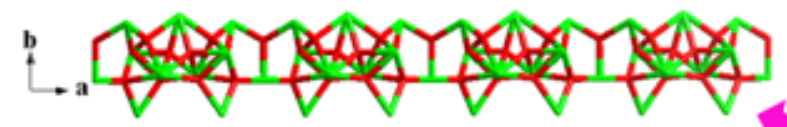

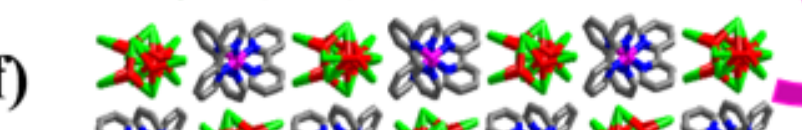

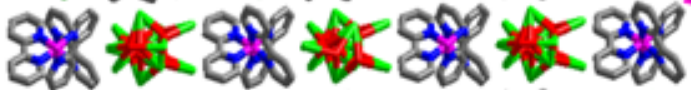

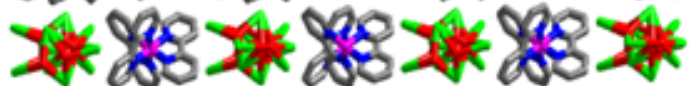

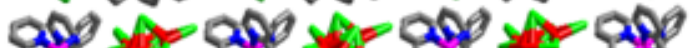

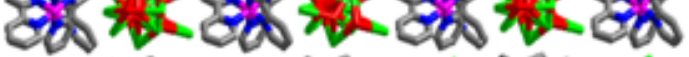

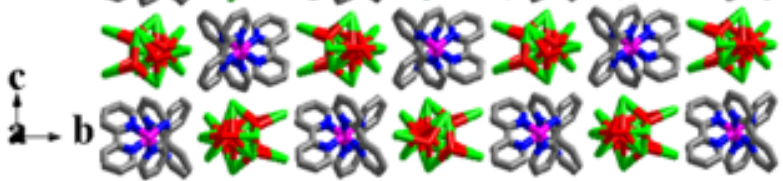

Figure 2

Compound 2: (a) The coordination environment of metal Co; (b) The coordination environment of metal Ag; (c) The connection of ligand 2, 2Х-bipy; (d) 1D chain structure; (e) 2D layered structure (\#1: 1-x, y, 0.5$\mathrm{z})$; (f) 2D layered structure (\#1: 1-x, y, 0.5-z) 

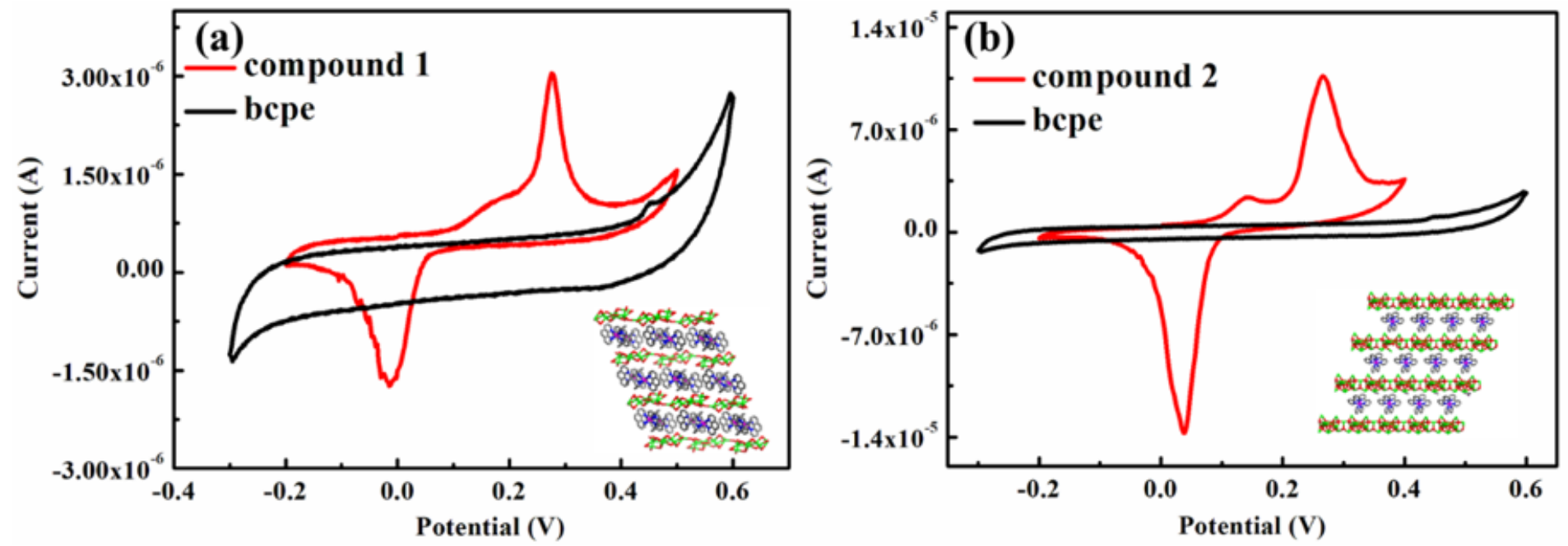

Figure 3

CV curves of bcpe and 1 and 2
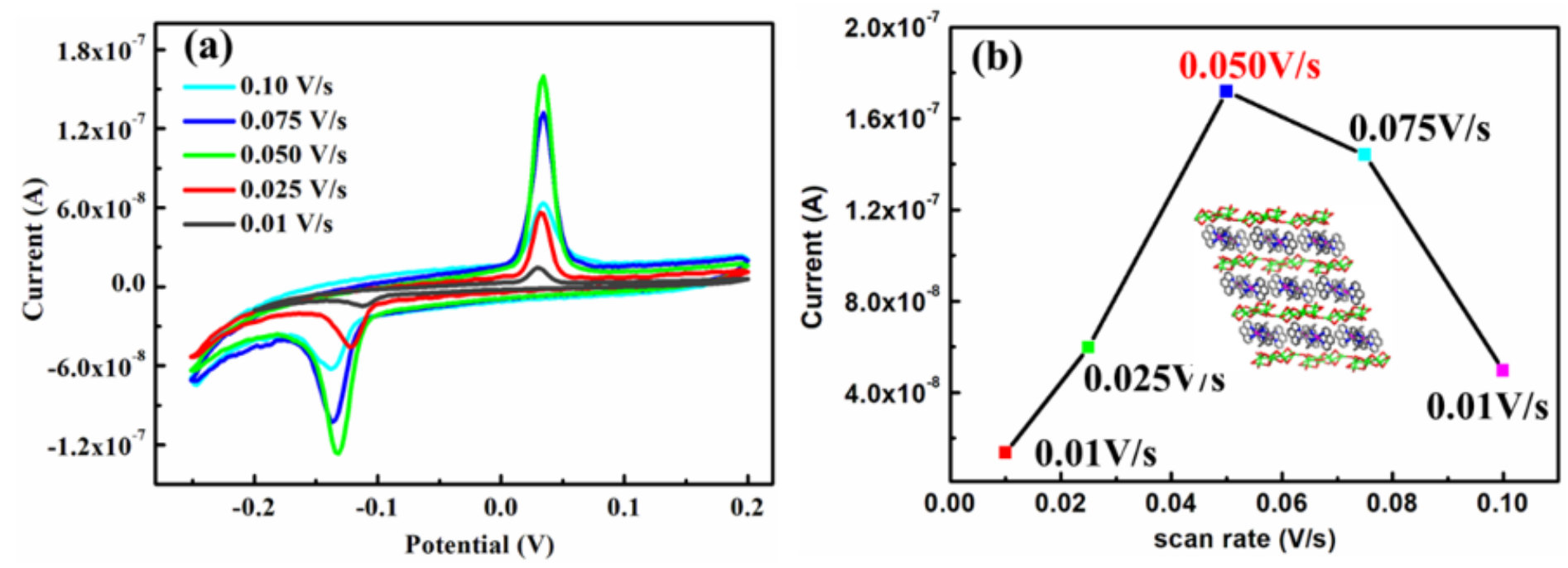

Figure 4

(a) CV curves of 1 at different scan rates; (b) The line chart of peak current at different scan rates of 1 

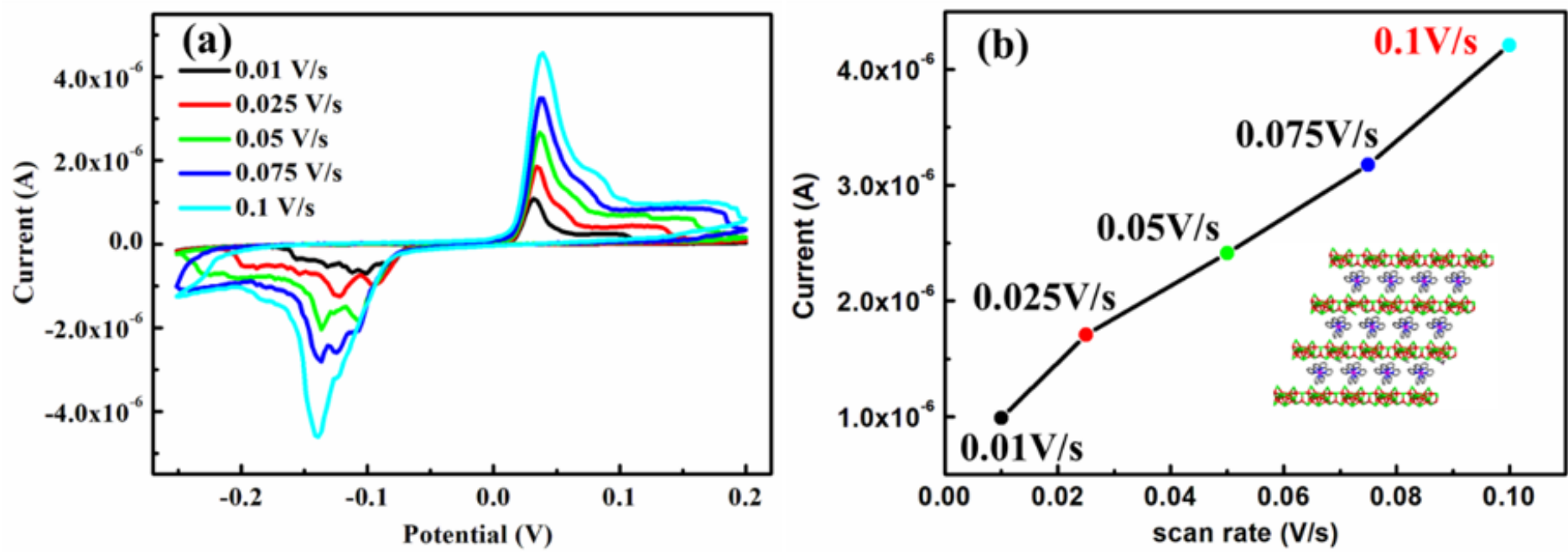

Figure 5

CV curves of 2 at different scan rates; (b) The line chart of peak current at different scan rates of 2
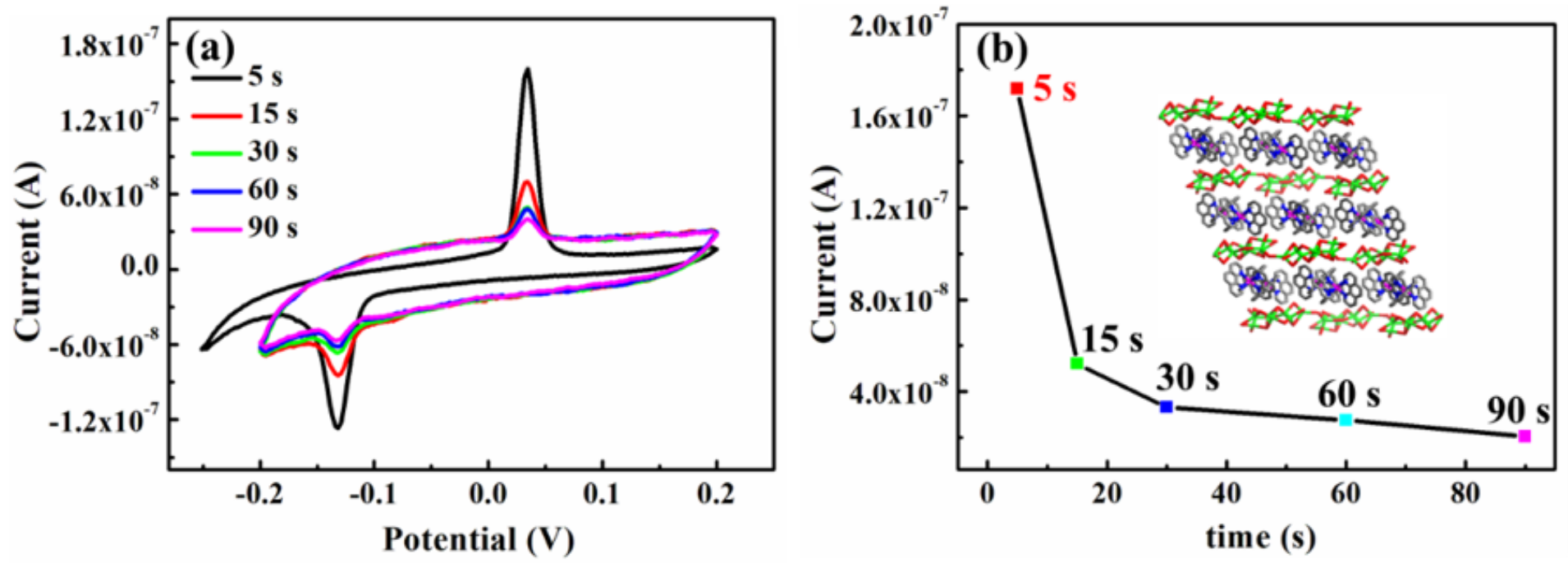

Figure 6

(a) CV curves of 1 at different time; (b) The line chart of peak current at different time of 1 

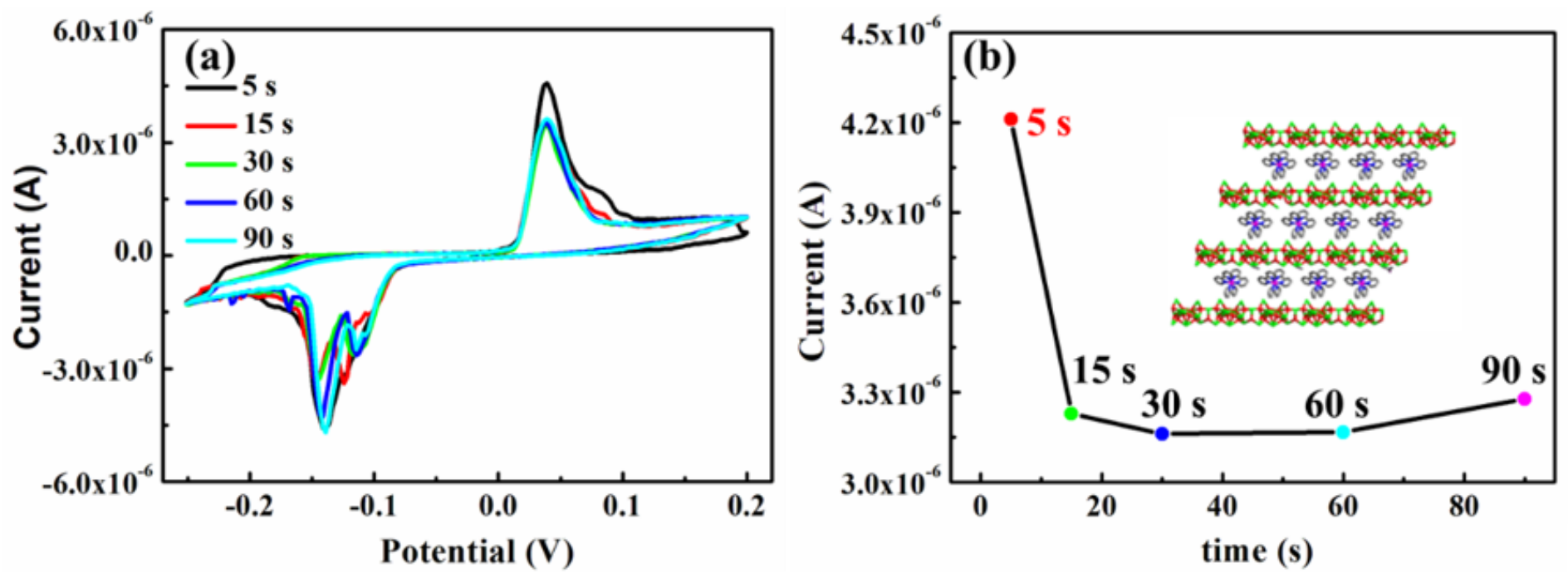

Figure 7

(a) CV curves of 2 at different time; (b) The line chart of peak current at different time of 2
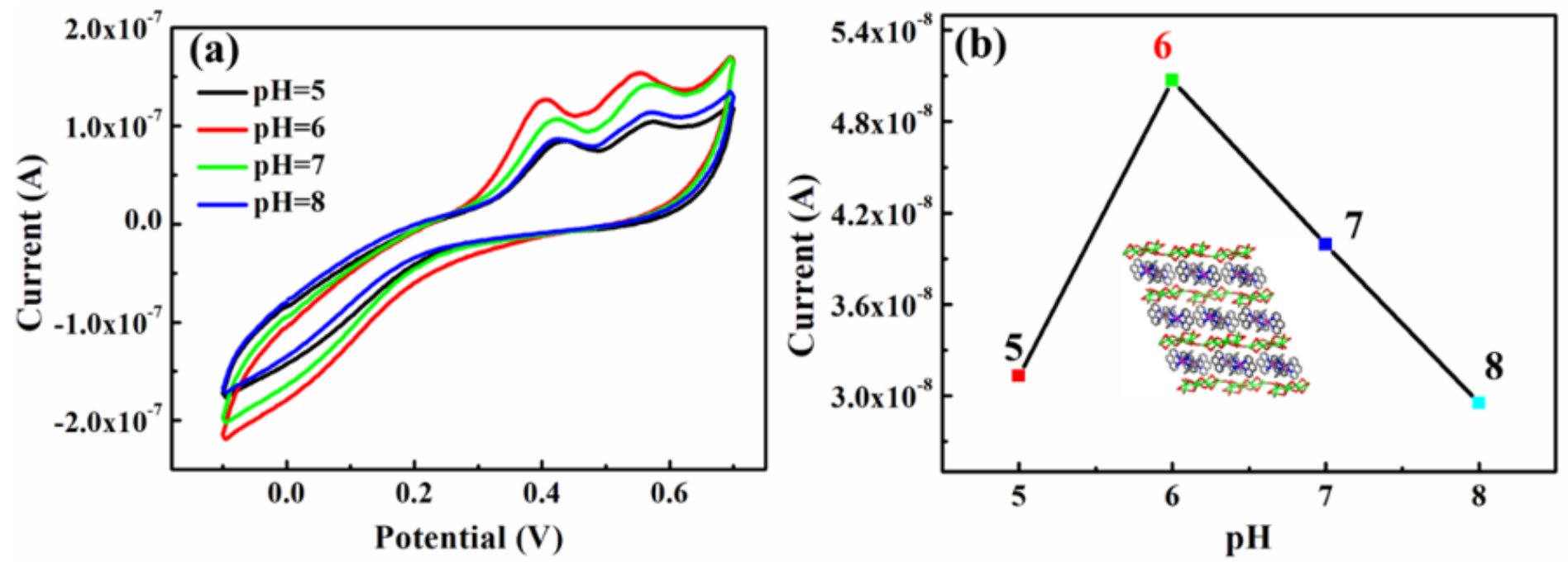

Figure 8

(a) CV curves of 1 at different $\mathrm{pH}$; (b) The line chart of peak current at different $\mathrm{pH}$ of 1 

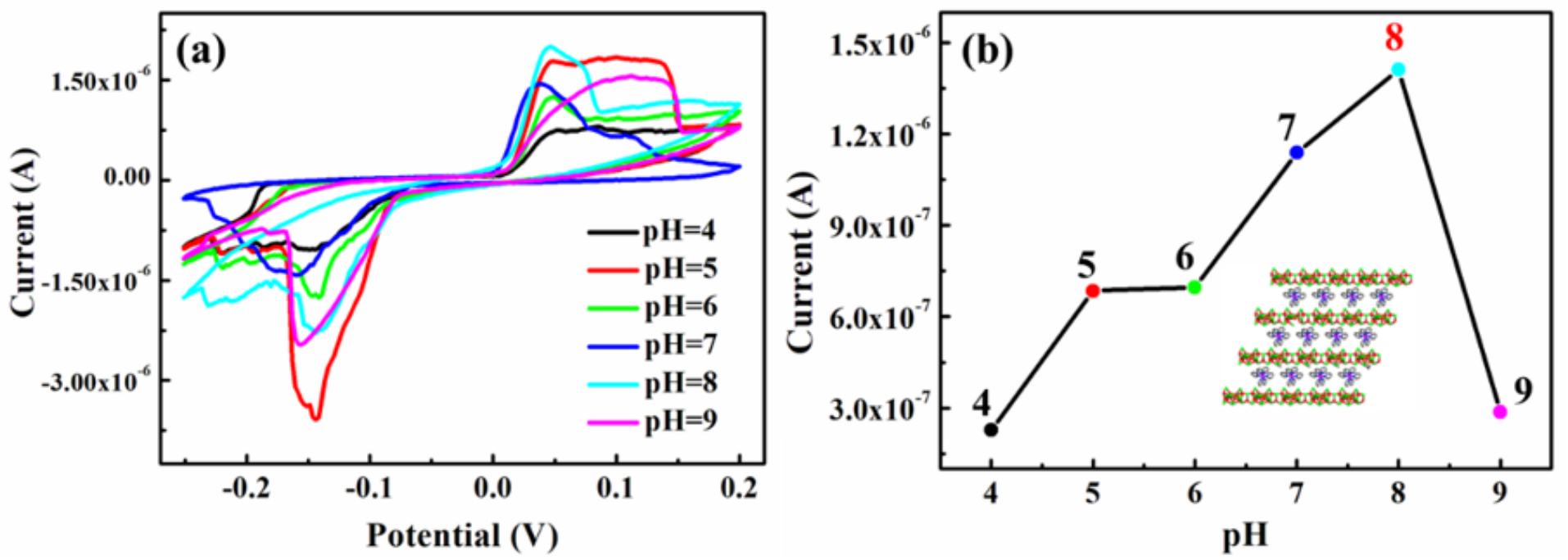

Figure 9

(a) CV curves of 2 at different $\mathrm{pH}$; (b) The line chart of peak current at different $\mathrm{pH}$ of 2
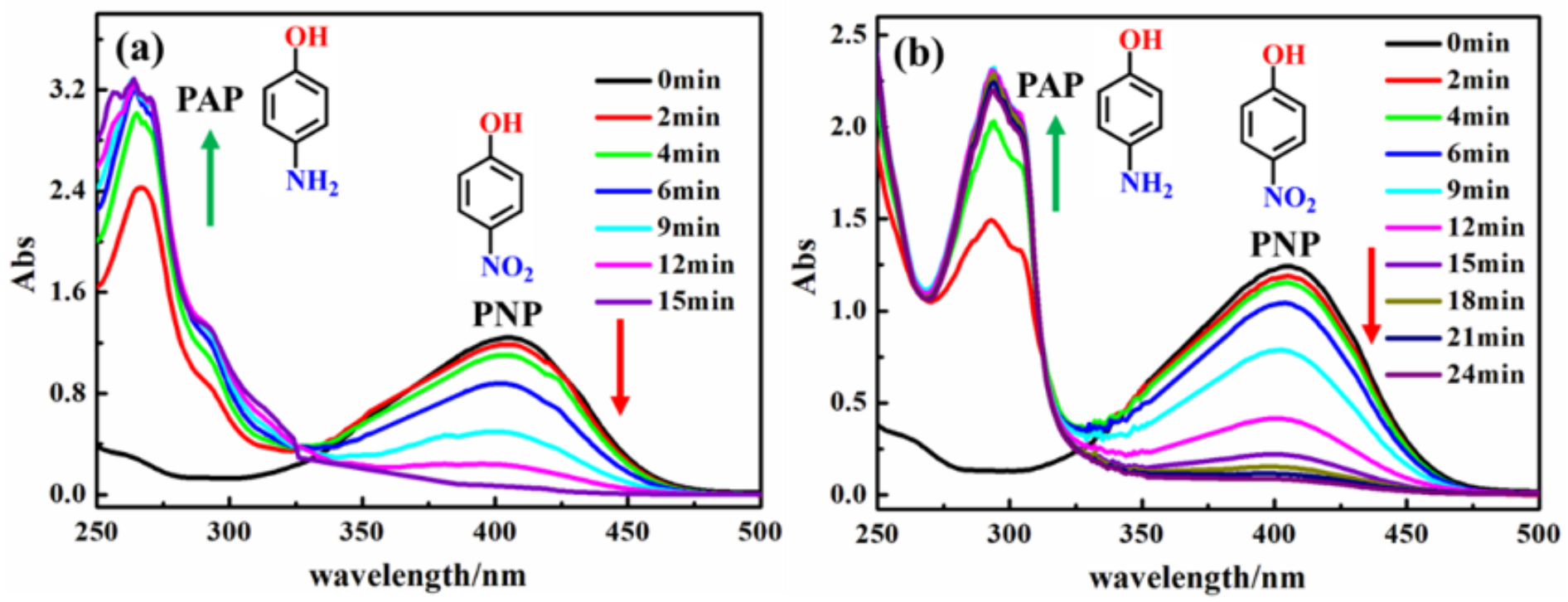

Figure 10

Curves of catalytic reduction of PNP: (a) 1 ; (b) 2 

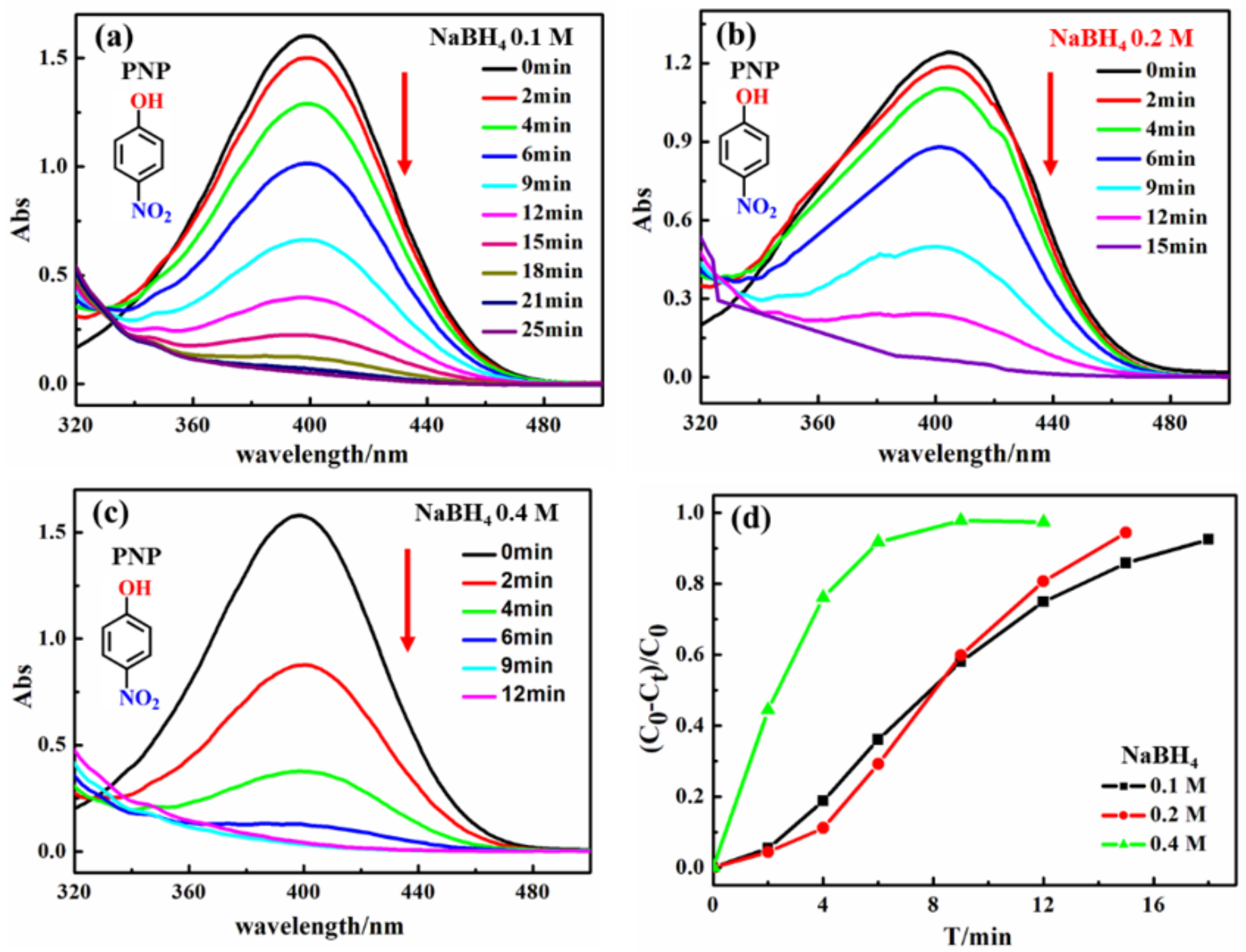

Figure 11

Effect of $\mathrm{NaBH} 4$ concentration on catalytic reduction of PNP with 1 : (a) $0.1 \mathrm{M}$; (b) $0.2 \mathrm{M}$; (c) $0.4 \mathrm{M}$; (d) Comparison of removal rates 

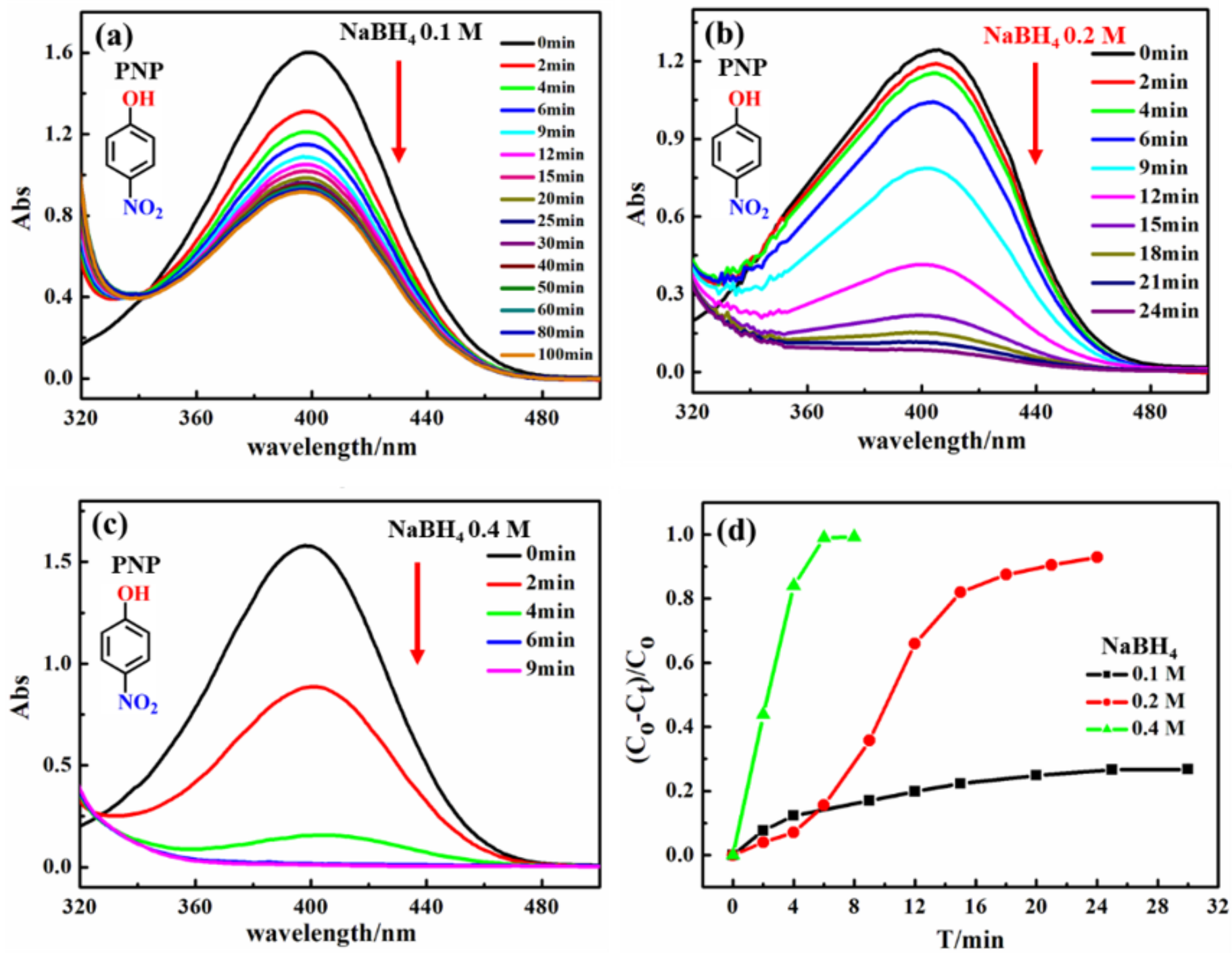

Figure 12

Effect of $\mathrm{NaBH} 4$ concentration on catalytic reduction of PNP with 2: (a) $0.1 \mathrm{M}$; (b) $0.2 \mathrm{M}$; (c) $0.4 \mathrm{M}$; (d) Comparison of removal rates 

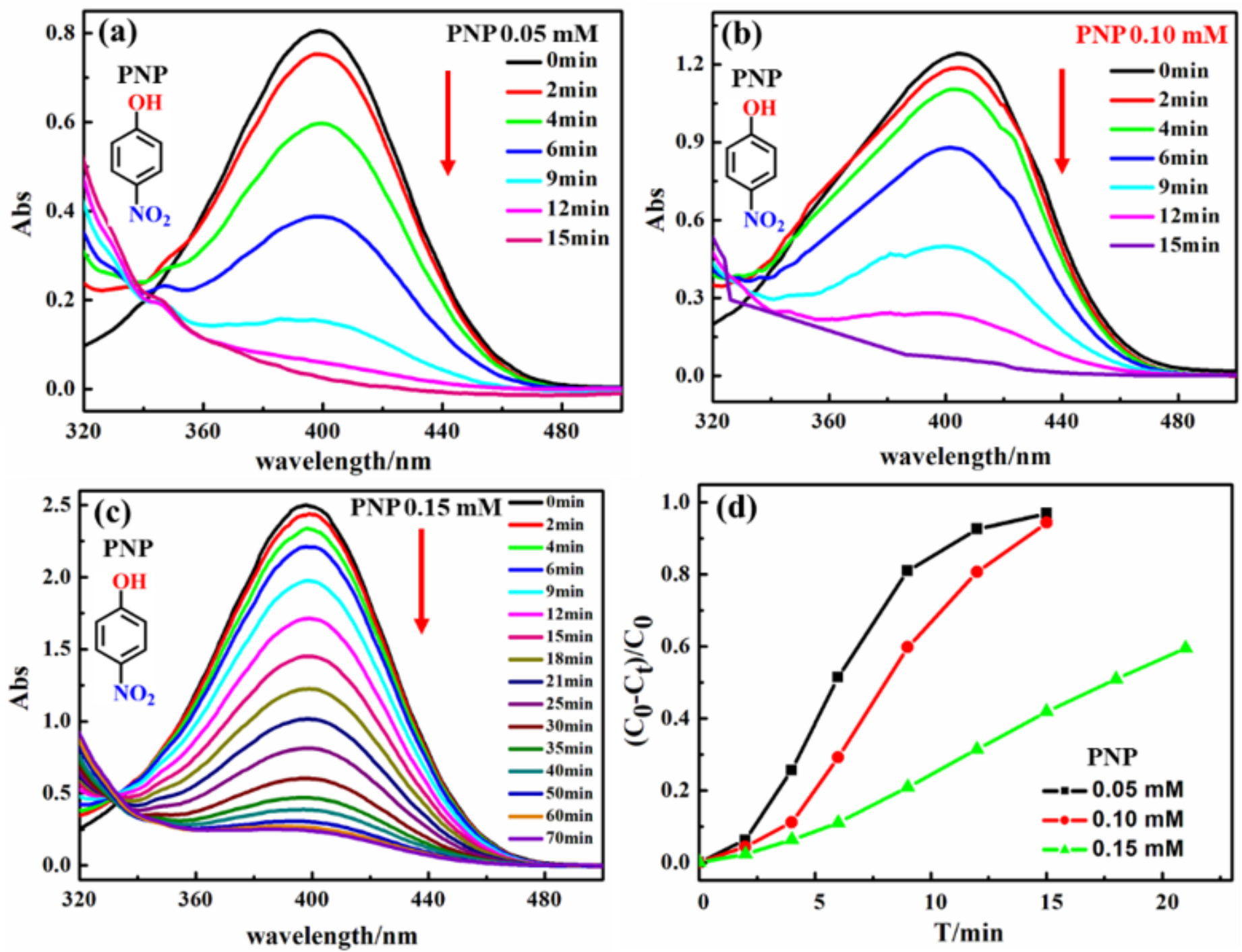

Figure 13

Effect of PNP concentration on catalytic reduction of PNP with 1: (a) $0.05 \mathrm{mM}$; (b) $0.1 \mathrm{mM}$; (c) $0.15 \mathrm{mM}$; (d) Comparison of removal rates 

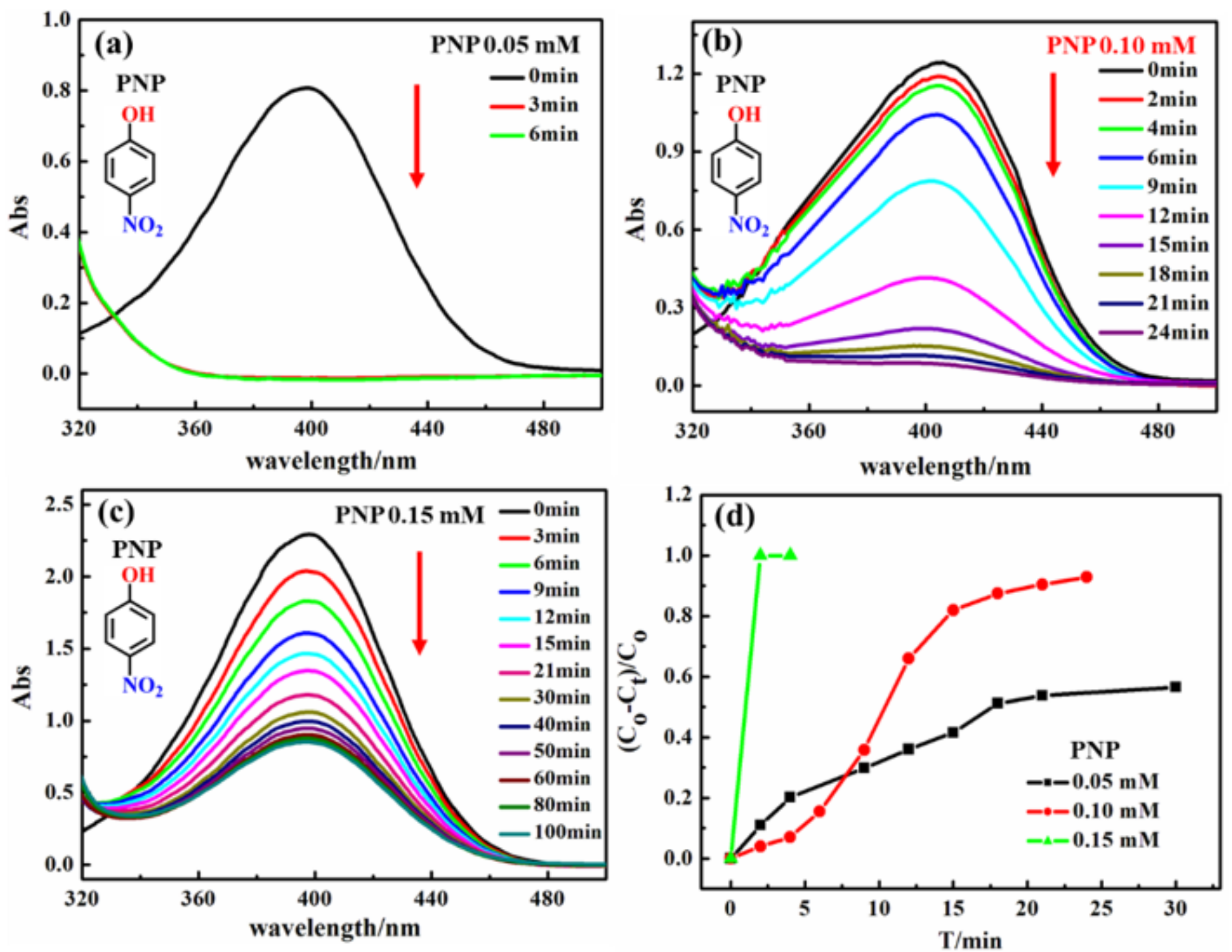

Figure 14

Effect of PNP concentration on catalytic reduction of PNP with 2: (a) $0.05 \mathrm{mM}$; (b) $0.1 \mathrm{mM}$; (c) $0.15 \mathrm{mM}$; (d) Comparison of removal rates 

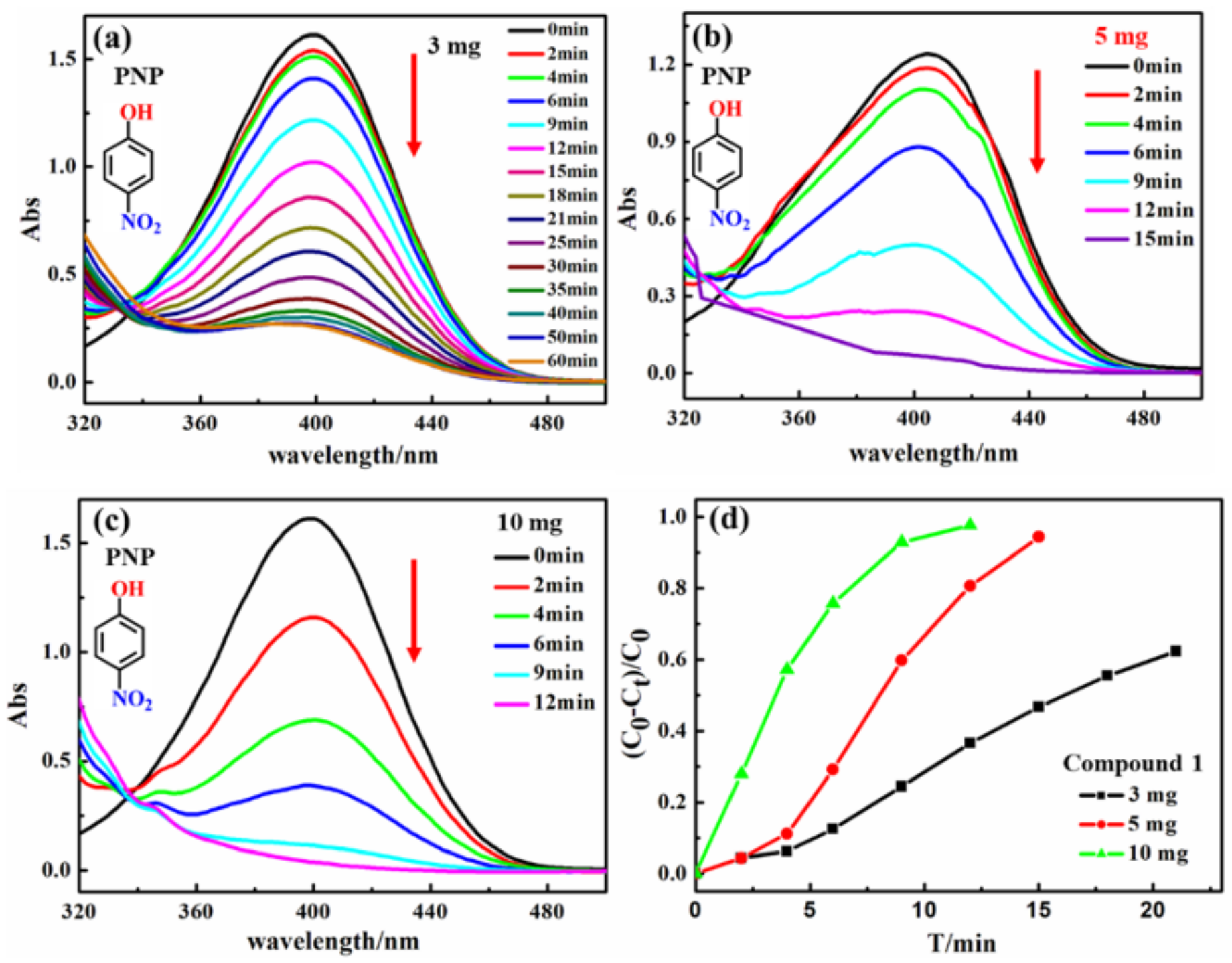

Figure 15

Effect of compound dose on catalytic reduction of PNP with 1: (a) 3 mg; (b) 5 mg; (c) 10 mg; (d) Comparison of removal rates of PNP in catalytic reduction of 1 with compound dose 

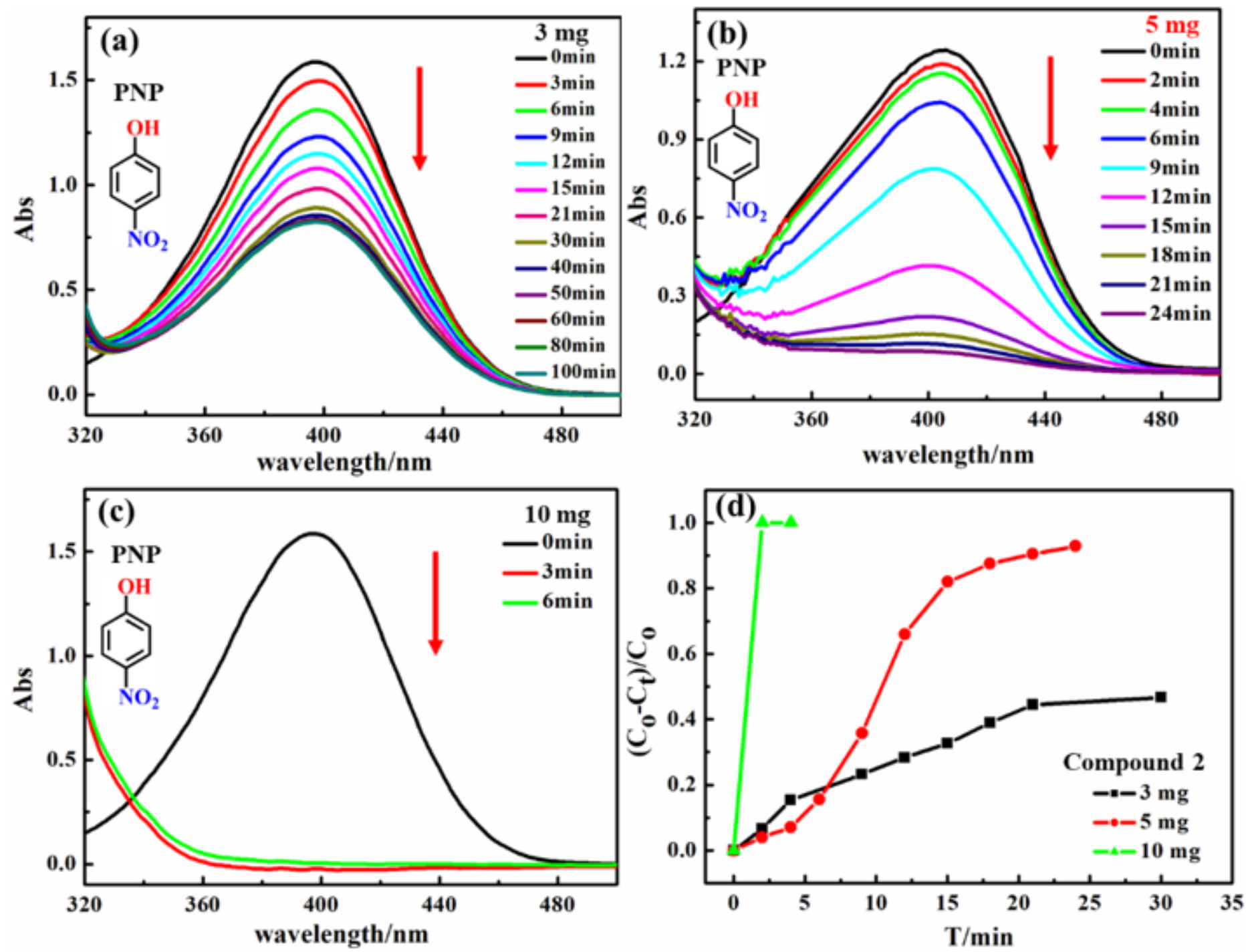

Figure 16

Effect of compound dose on catalytic reduction of PNP with 2: (a) $3 \mathrm{mg}$; (b) $5 \mathrm{mg}$; (c) $10 \mathrm{mg}$; (d) Comparison of removal rates of PNP in catalytic reduction of 2 with compound dose 

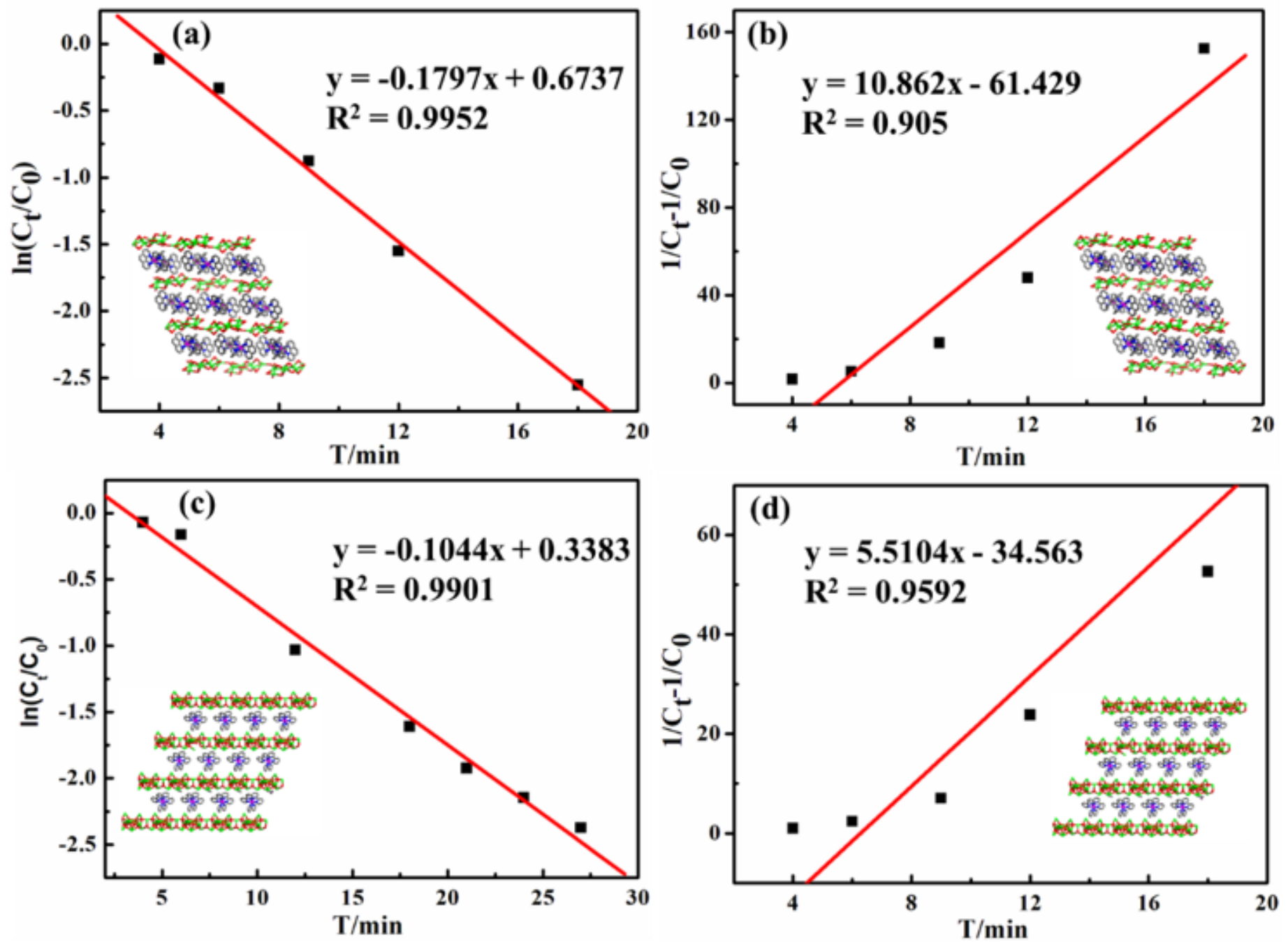

Figure 17

(a) Pseudo-first-order kinetic curves of catalytic reduction of PNP with 1; (b)Pseudo-second-order kinetic curves of catalytic reduction of PNP with 1; (c) Pseudo-first-order kinetic curves of catalytic reduction of PNP with 2; (d) Pseudo-second-order kinetic curves of catalytic reduction of PNP with 2 


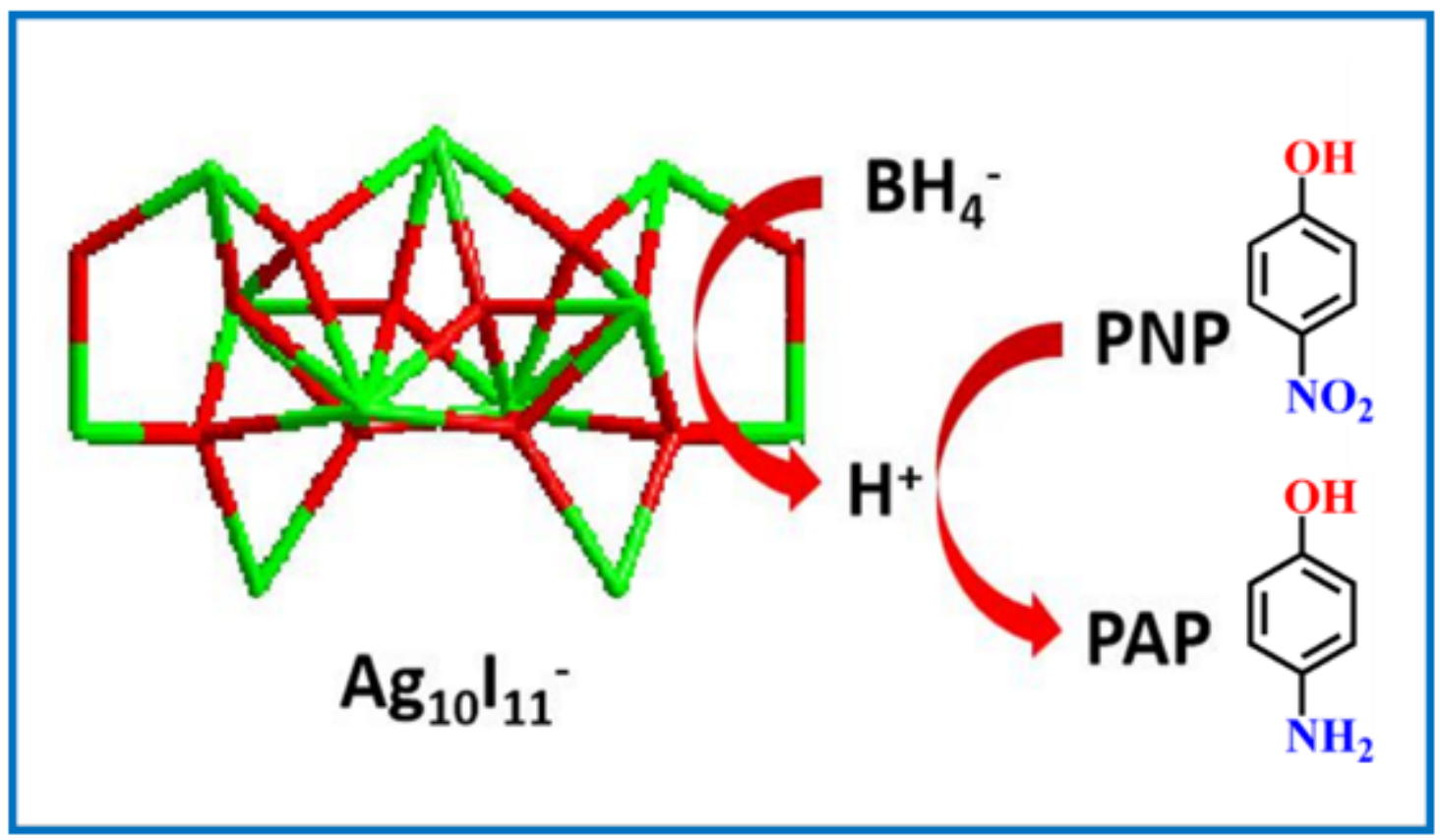

Figure 18

Mechanism of catalytic reduction of PNP

\section{Supplementary Files}

This is a list of supplementary files associated with this preprint. Click to download.

- 1.pdf

- 2.pdf

- Supportinginformation.docx

- TOC.docx 